\title{
ANAIS DO I CONGRESSO DOS ESTUDANTES DE GRADUAÇÃO E TÉCNICO DE ENFERMAGEM DO AMAZONAS/ IV ENCONTRO AMAZONENSE DOS ESTUDANTES DE ENFERMAGEM
}

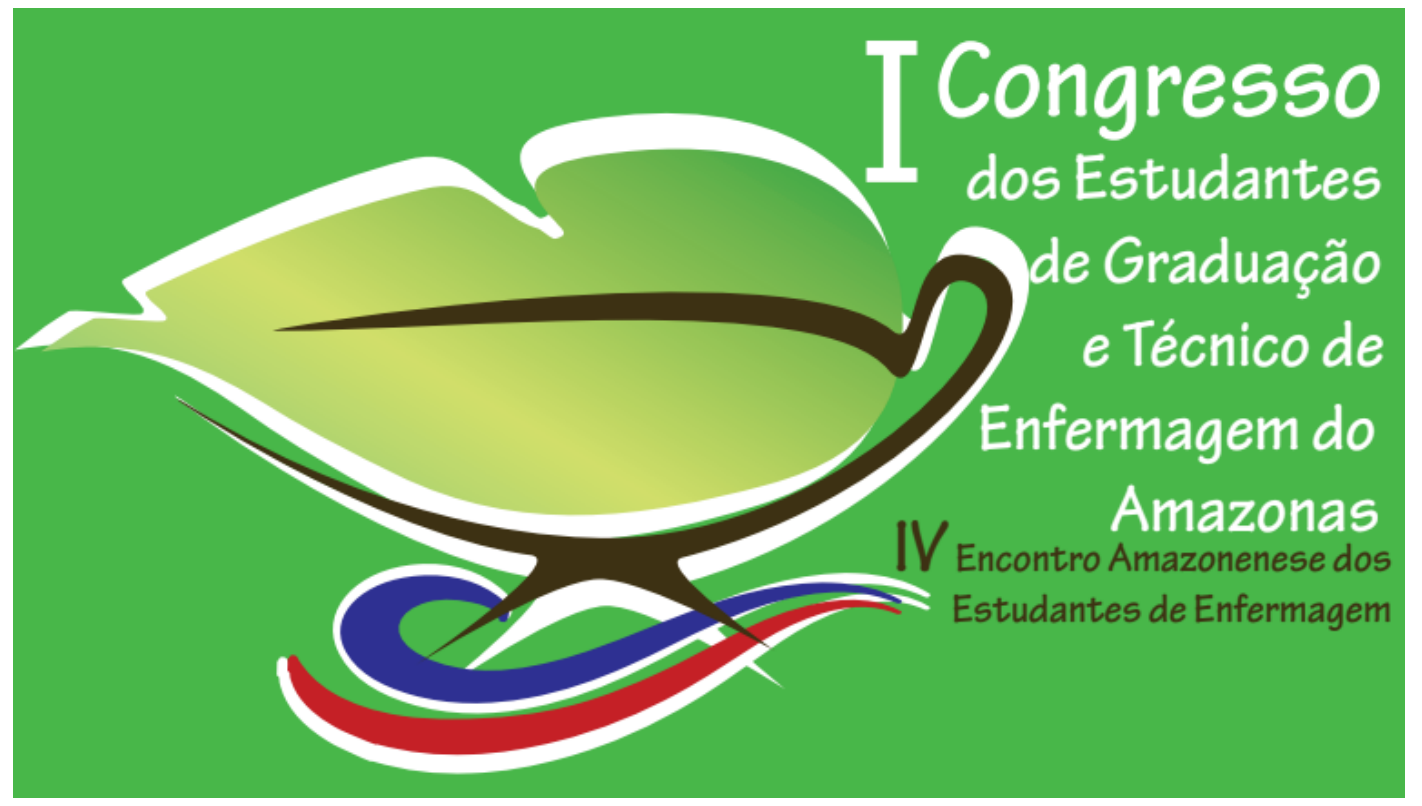

TEMA: CUIDADO EM SAÚDE: POSSIBILIDADES DE ATUAÇÃO DA EQUIPE DE ENFERMAGEM

DOI: $10.25248 /$ REAS-ANAIS-e815.2018

\section{APOIO:}

\section{ACERVO Mals ieristas} www.acervomais.com.br

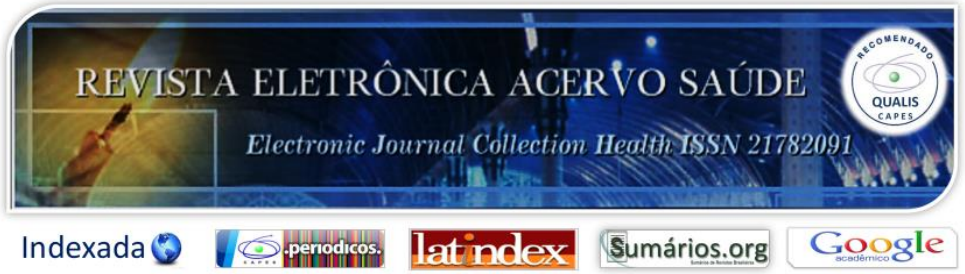



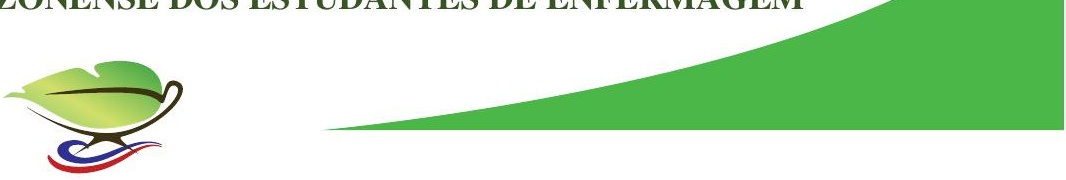

\section{APRESENTAÇÃO}

O I Congresso dos Estudantes de Graduação e Técnico de Enfermagem do Amazonas acontece no ano de 2018 somado à IV edição do Encontro Amazonense dos Estudantes de Enfermagem, a partir de grandes esforços dos estudantes do ensino técnico e superior da enfermagem amazonense para garantir a representatividade estudantil, visando ao empoderamento da classe para a efetivação de conquistas em prol da valorização da maior classe profissional da saúde no Brasil.

Todo um processo histórico antecedeu a realização deste evento, considerado um marco no movimento estudantil local. A raiz da representatividade estudantil em enfermagem no Amazonas surge com a implantação do primeiro centro Acadêmico de Enfermagem, pertencente à Universidade Federal do Amazonas. Posteriormente, outros centros acadêmicos surgem: respectivamente, o da Universidade do Estado do Amazonas, Universidade Luterana de Manaus e Universidade Nilton Lins.

A primeira edição do Encontro Amazonense dos Estudantes de Enfermagem foi realizada no ano de 2014 por um dos Centros Acadêmicos. No ano de 2017, com a implantação do Comitê Estudantil da Associação Brasileira de Enfermagem Seção Amazonas, os centros acadêmicos juntos realizaram a terceira edição do evento. Posteriormente, já no ano de 2018, o Fórum Amazonense de Representatividade Estudantil em Enfermagem foi o ponto de idealização do I Congresso dos Estudantes de Graduação e Técnicos de Enfermagem do Amazonas.

O tema escolhido foi "cuidado em saúde: possibilidades de atuação da equipe de enfermagem", com a finalidade de promover o aprimoramento científico-cultural da classe estudantil do curso de graduação e técnico de enfermagem, visando ao fomento do contato interinstitucional entre os estudantes da categoria no estado do Amazonas.

O lema adotado para a divulgação do evento foi :"Um evento feito por estudantes, para estudantes!", frase que carregou a grande empolgação de uma comissão de cerca de 30 estudantes ávidos por conquistas e novos horizontes para o movimento estudantil em enfermagem. Com essa disposição, seguiu-se uma caminhada de alguns meses que resultaram na inscrição de cerca de 500 estudantes. 
O Congresso foi realizado no Auditório Eulálio Chaves da Universidade Federal do Amazonas nos dias 25 e 26 outubro de 2018 e contou com o apoio das duas entidades de classe, Associação Brasileira de Enfermagem - Seção Amazonas, e Conselho Regional de Enfermagem do Amazonas, além de diversas instituições comprometidas com a formação dos Enfermeiros e Técnicos de enfermagem do estado e País.

A comissão científica esteve dedicada à atuação frente aos trabalhos submetidos e apresentados. No total, foram 63 resumos submetidos nos três eixos centrais: Eixo I: A enfermagem frente ao cuidado no Sistema Único de Saúde; Eixo II: Áreas de atuação dos profissionais de enfermagem; Eixo III: Formação da equipe de enfermagem para o cuidado em saúde.

Os trabalhos passaram pela avaliação de profissionais da área com coordenação do Doutor Esron Soares Carvalho Rocha e, após apresentação, passaram pelas recomendações para constarem nos anais do evento. Vale salientar a grande satisfação de contar com o apoio da Revista Acervo Saúde neste processo que visa tornar a enfermagem amazonense ainda mais próxima das práticas científicas atuais.

Por fim, a realização deste evento esteve alicerçada no comprometimento de uma classe estudantil ciente de sua responsabilidade para o engrandecimento da Enfermagem Brasileira e, consequentemente, com a saúde da população assistida pelo sistema público e privado de saúde, salientando o papel de protagonismo da profissão no SUS. A luta continua, o compromisso com as bandeiras de luta da classe será mantido e a disposição para conquista de novos espaços é a motivação atual, resistindo sobre os medos impostos através dos obstáculos e acreditando que a enfermagem pode ser sempre mais! 
ANAIS DO I CONGRESSO DOS ESTUDANTES DE GRADUAÇÃO E TÉCNICO DE ENFERMAGEM DO AMAZONAS/ IV ENCONTRO AMAZONENSE DOS ESTUDANTES DE ENFERMAGEM

\section{ORGANIZAÇÃ̃O}
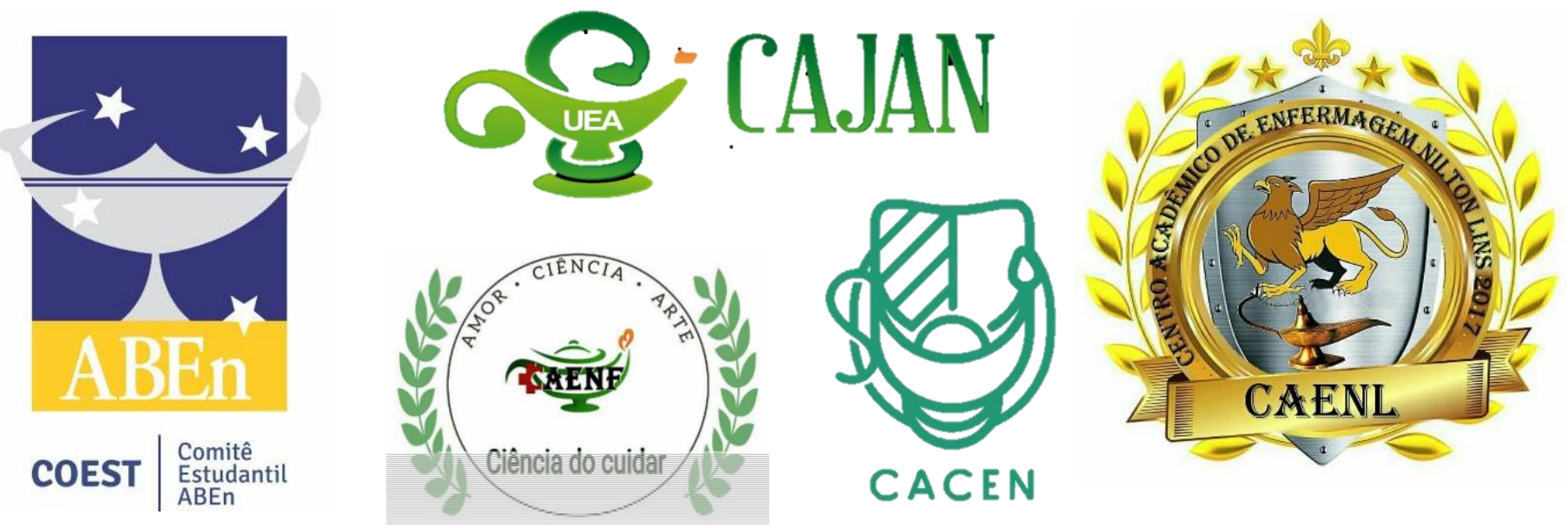

\section{APOIADORES DO EVENTO}
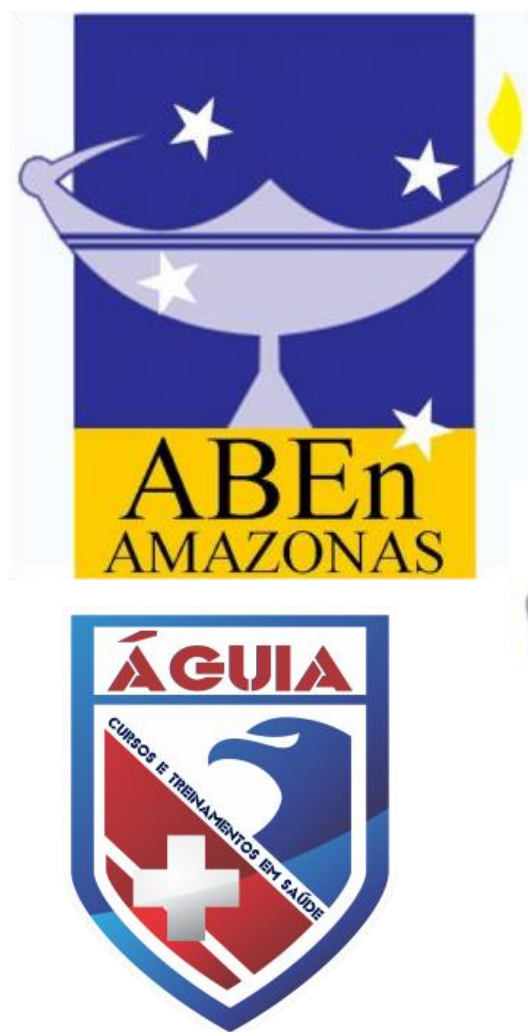
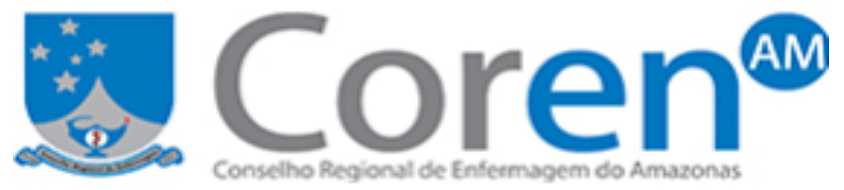

SINGULAR EDUCACIONAL

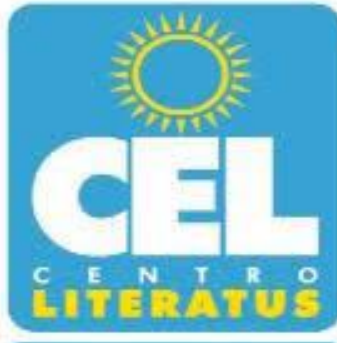

EDUCAC̆ÃO PROFISSIONAL

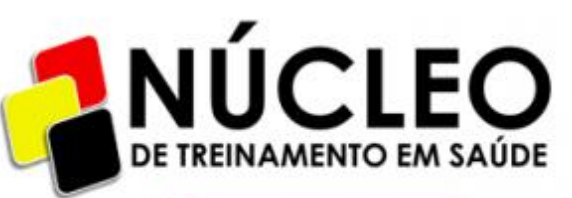

(C) $98136-4516$

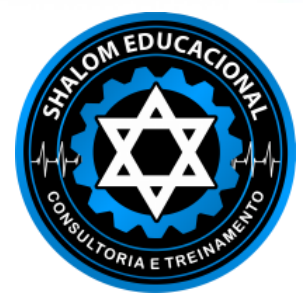

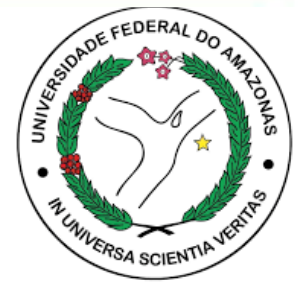

UFAM 


\section{PRESIDENTE DA COMISSÃO ORGANIZADORA}

Iago Orleans Pinheiro Monteiro

\section{PRESIDENTE DA COMISSÃO CIENTÍFICA}

Esron Soares Carvalho Rocha

\section{COMISSÃO DIRETORA}

- $\quad$ Ashley de Matos Souza

- Dioneia Silva de Castro

- $\quad$ Everton de Oliveira Pinto

- $\quad$ Francisco Diermis Paulo de Oliveira

- $\quad$ George Lucas Augusto Trindade da Silva

- $\quad$ Hugo Nepomuceno Rocha

- $\quad$ Izaura Jacob Gonçalves

- $\quad$ Karoline Costa de Souza

- $\quad$ Mônica Silva de Souza

- $\quad$ Nany Camilla Sevalho Azuelo

\section{COMISSÃO ORGANIZADORA}

1. Alessandro Barbosa de Andrade

2. Alice Lima Maceda

3. André Luiz Silvino Corrêa

4. Ariella Auxiliadora Barroso Pires dos Santos

5. Beatriz Ferreira Monteiro

6. Ciro Judah Vargas Batista de Mendonça

7. David Brendo Souza Damião

8. Douglas Siqueira de Brito 
9. Elienay Campos Vinholt

10. Evandro do Nascimento Pinheiro

11. Gabriele Pimentel Sinimbu

12. Giovana Nogueira Torres

13. Isabella Soares Pinheiro Pinto

14. Izaura Jacob Gonçalves

15. Janaína da Silva Santana

16. Jhonas Carvalho dos Santos

17. Luany da Silva Gomes

18. Lucas Pereira da Costa

19. Marcela Catunda de Souza Michiles

20. Mateus Gomes da Silva

21. Matheus dos Santos Matos

22. Rafaela Paixão Sales

23. Silvia Aparecida da Silva

\section{COMISSÃO CIENTÍFICA}

1. Ana Carolina de Oliveira Souza

2. Larissa Amorim Mendonça Belido

3. Robson de Oliveira Félix

4. Thais Gomes de Oliveira

5. Tracy Anne Ferreira de Oliveira Guimarães

6. Wanessa Souza Barbosa 


\title{
PROGRAMAÇÃO
}

\section{CONGRESSO DOS ESTUDANTES DE GRADUAÇÃO E TÉCNICOS DE ENFERMAGEM DO AMAZONAS}

\author{
"Cuidado em Saúde: Possibilidade de atuação da \\ equipe de Enfermagem"$$
1^{0} \text { dia - 25/0ut }
$$

7 h30 - Credenciamento do evento - Auditório Eulálio Chaves

$8 \mathrm{~h}$ - Cerimônia de Abertura

9h - Conferência 1 - "Movimento Estudantil: A Educaçāo Frente à Formaçāo Política para as boas práticas de enfermagem"

$10 \mathrm{~h}$ - Conferência 2 - "Formaçāo profissional da equipe de enfermagem"

$14 \mathrm{~h}$ às $18 \mathrm{~h}$ - Apresentaçāo de Trabalhos Científicos - Instituto de Ciências Biológicas (ICB) Salas 08 e 16

$$
2^{0} \text { dia - 26/out }
$$

08h às 10h-TALK-SHOW: POSSIBILIDADES DE ATUAÇĀO DO TÉCNICO DE ENFERMAGEM

$$
\text { Auditório Eulálio Chaves }
$$

10h às $12 \mathrm{~h}$ - Oficinas:

1. Estilos de vida na enfermagem: do estudante ao profissional - Programa de Pós-graduaçāo em Imunologia Básica e aplicada (Auditório)

2. Política nacional de atençāo básica: Espaço de atuaçāo da equipe de enfermagem - Faculdade de Ciências Farmacêuticas (Auditório)

3. Cuidado em saúde frente às situaçōes de gênero - Instituto de Ciências Biológicas (Auditório Paulo Buhrheim)

4. Centros acadêmicos: 0 que sāo e o que fazem? - Instituo de Ciências Biológicas (sala 7)

$12 \mathrm{~h}-14 \mathrm{~h}$ - Almoço

14h às 17h - UM DEDO DE PROSA: Responsabilidade, Ética Cível e Penal dos Profissionais de Enfermagem

Auditório Eulálio Chaves

17h - Encerramento- Premiaçāo dos Trabalhos Destaques

18h - Atraçāo Cultural - Cuidando com o Canto

CONFIRA NOSSOS SITE E REDES SOCIAIS 


\section{$\overbrace{0}$ SUMÁRIO}

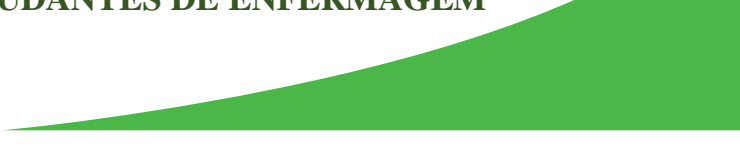

\section{EIXO 1: A ENFERMAGEM FRENTE AO CUIDADO NO SISTEMA ÚNICO DE} SAÚDE

ESTRATÉGIAS EDUCATIVAS EM SAÚDE PARA ADOLESCENTES COM HIV/AIDS:

UM RELATO DA EXPERIÊNCIA DE ACADÊMICOS DE ENFERMAGEM DA UEA ...... 12

A PERCEPÇÃO DE ACADÊMICAS DE ENFERMAGEM DIANTE DAS PRÁTICAS ASSISTENCIAIS NO PERÍODO PÓS-OPERATÓRIO EM UMA ENFERMARIA CIRÚRGICA: RELATO DE EXPERIÊNCIA.

RELATO DE EXPERIÊNCIA: PLANEJANDO A FAMÍLIA, ESCOLHA DO MÉTODO EFICAZ COM A AJUDA DA ENFERMAGEM DA ATENÇÃO BÁSICA. ........................... 16

O BRINQUEDO TERAPÊUTICO NO AMBIENTE HOSPITALAR

O ENFERMEIRO COMO INTEGRANTE FUNDAMENTAL NA DEFESA DO SISTEMA ÚNICO DE SAÚDE SUS: UM RELATO DE EXPERIÊNCIA

PERCEPÇÃO DE ACADÊMICOS DE ENFERMAGEM NA EMERGÊNCIA DE UM HOSPITAL PÚBLICO NO INTERIOR DO AMAZONAS: UM RELATO DE EXPERIÊNCIA

A UTILIZAÇÃO DOS MÉTODOS NÃO FARMACOLÓGICOS PELO ENFERMEIRO OBSTETRA PARA ALÍVIO DA DOR DURANTE O TRABALHO DE PARTO EM MATERNIDADES PÚBLICAS DO BRASIL

O TRANSTORNO DO ESPECTRO DO AUTISMO SOB A PERSPECTIVA DO CUIDADO PÓS-REFORMA PSIQUIÁTRICA.

RELATO DE EXPERIÊNCIA: A IMPORTÂNCIA DO ACOLHIMENTO E ORIENTAÇÃO PARA A COLETA DO EXAME PAPANICOLAU .

TERAPIA COMUNITÁRIA INTEGRATIVA: UMA MÉTODOLOGIA DE PROMOÇÃO DE SAÚDE MENTAL EM UM CENTRO DE ATENÇÃO PSICOSSOCIAL DA CIDADE DE MANAUS

PERCEPÇÃO DOS ENFERMEIROS SOBRE OS CUIDADOS E PREVENÇÃO DAS ÚLCERAS POR PRESSÃO EM PACIENTES HOSPITALIZADOS

EIXO 2: ÁREAS DE ATUAÇÃO DOS PROFISSIONAIS DE ENFERMAGEM... 34

EDUCAÇÃO EM SAÚDE COMO FERRAMENTA PARA O CUIDADO: UMA EXPERIÊNCIA COM CUIDADORES DE IDOSOS

APLICAÇÃO DE ATIVIDADE LÚDICA COMO ESTRATÉGIA NA PROPAGAÇÃO DO SABER E DO CUIDADO DE ENFERMAGEM NA SAÚDE MENTAL: RELATO DE EXPERIÊNCIA

O OLHAR DO ACADÊMICO DE ENFERMAGEM SOBRE A ATUAÇÃO DO

ENFERMEIRO NO CENTRO DE PARTO NORMAL INTRA-HOSPITALAR: UM RELATO

DE EXPERIENCIA.

CUIDADOS DE ENFERMAGEM NA ATENÇÃO À PESSOA IDOSA: RELATO DE 
ANAIS DO I CONGRESSO DOS ESTUDANTES DE GRADUAÇÃO E TÉCNICO DE ENFERMAGEM DO AMAZONAS/ IV ENCONTRO AMAZONENSE DOS ESTUDANTES DE ENFERMAGEM

O SETEMBRO AMARELO E A CAMINHADA PELA VIDA: RELATO DE EXPERIÊNCIA

A EDUCAÇÃO EM SAÚDE COMO FERRAMENTA PARA FALAR DE MENINGITE: UM RELATO DE EXPERIÊNCIA 45

A IMPORTÂNCIA DA MONITORIA ACADÊMICA COMO ESPAÇO NA ÁREA DA DOCÊNCIA: RELATO DE EXPERIÊNCIA

DESENVOLVIMENTO DE UM SOFTWARE GUIADO PELO PROCESSO DE ENFERMAGEM PARA AUXILIAR O ENFERMEIRO NA AVALIAÇÃO E TRATAMENTO DE LESÃO POR PRESSÃO .49

PERCEPÇÃO DOS IDOSOS EM RELAÇÃO AO CONVÍVIO EM INSTITUIÇÕES DE LONGA PERMANÊNCIA

PERCEPÇÃO DE ACADÊMICOS DE ENFERMAGEM FRENTE À VIVÊNCIA DE PRÁTICAS EDUCATIVAS COM CRIANÇAS NA CRECHE

RELATO DE EXPERIÊNCIA: EDUCAÇÃO EM SAÚDE SOBRE PRÁTICAS RESPIRATÓRIAS NA ÓTICA DE ACADÊMICOS DE ENFERMAGEM.

RELATO DE EXPERIÊNCIA: IMPRESSÕES SOBRE A INSERÇÃO DA REALIDADE VIRTUAL EM SAÚDE NA DISCIPLINA PRÁTICAS INTEGRADAS EM UM CURSO DE ENFERMAGEM NO AMAZONAS.

OCORRÊNCIA DE PNEUMONIAS NOSOCOMIAIS ASSOCIADAS À VENTILAÇÃO MECÂNICA EM PACIENTES INTERNADOS EM UNIDADES DE TERAPIA INTENSIVA DE UM HOSPITAL ESPECIALIZADO EM DOENÇAS TROPICAIS DE MANAUS .......... 59

EIXO 3: FORMAÇÃO DA EQUIPE DE ENFERMAGEM PARA O CUIDADO EM SAÚDE 61

TUMOR DE WILMS: PERCEPÇÃO ACADÊMICA ACERCA DO CÂNCER PEDIÁTRICO

A VIVÊNCIA EM PROJETO EDUCATIVO: ENSINO SOBRE DOENÇAS TROPICAIS ... 64 CAPACITAÇÃO E DOCÊNCIA: UMA VIA DE MÃO DUPLA 66 A IMPORTÂNCIA DAS PRÁTICAS DE ENFERMAGEM PARA O APRIMORAMENTO DOS EGRESSOS DO CURSO DE ENFERMAGEM: UM OLHAR CRÍTICO REFLEXIVO68 AS DIFICULDADES VIVENCIADAS POR ACADÊMICOS DE ENFERMAGEM FRENTE AO ENSINO E PESQUISA: UM RELATO DE EXPERIÊNCIA .70 VIVÊNCIA DAS ACADÊMICAS DE ENFERMAGEM COM A TELESTOMATERAPIA SENDO FERRAMENTA DE ESTUDO E AMPLIAÇÃO DE CONHECIMENTOS: UM RELATO DE EXPERIÊNCIA.

EDUCAÇÃO EM SAÚDE SOBRE CONSUMO DE SAL E AÇUCAR COM ESCOLARES: UM RELATO DE EXPERIÊNCIA. .73

CONTRIBUIÇÕES DA MONITORIA PARA O PROCESSO DE FORMAÇÃO ACADÊMICA DO ENFERMEIRO - RELATO DE EXPERIÊNCIA 75

VIVÊNCIAS DE ACADÊMICOS DE ENFERMAGEM EM UMA UNIDADE DE TERAPIA INTENSIVA. 
ANAIS DO I CONGRESSO DOS ESTUDANTES DE GRADUAÇÃO E TÉCNICO DE ENFERMAGEM DO AMAZONAS/ IV ENCONTRO AMAZONENSE DOS ESTUDANTES DE ENFERMAGEM

PROMOVENDO SAÚDE PARA CRIANÇAS POR MEIO DE MATERIAIS LÚDICOS EM UMA ESCOLA NO INTERIOR DO AMAZONAS …………………………………..... 79 A VIVÊNCIA DO ACADÊMICO DE ENFERMAGEM NA PRÁTICA DA DISCIPLINA DE ENFERMAGEM NO PROCESSO DE CUIDAR NA SAÚDE MENTAL …………………... 81 
ANAIS DO I CONGRESSO DOS ESTUDANTES DE GRADUAÇÃO E TÉCNICO DE ENFERMAGEM DO AMAZONAS/ IV ENCONTRO AMAZONENSE DOS ESTUDANTES DE ENFERMAGEM

\section{RESUMOS}

\section{EIXO 1: A ENFERMAGEM FRENTE AO} CUIDADO NO SISTEMA ÚNICO DE SAÚDE

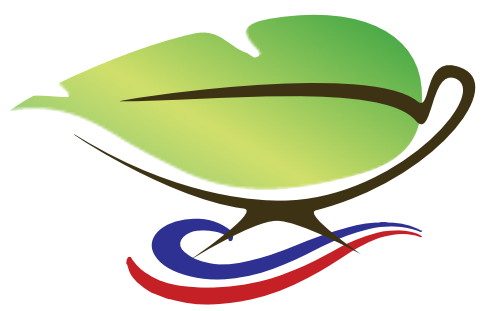




\title{
ESTRATÉGIAS EDUCATIVAS EM SAÚDE PARA ADOLESCENTES COM HIV/AIDS: UM RELATO DA EXPERIÊNCIA DE ACADÊMICOS DE ENFERMAGEM DA UEA
}

\author{
Thiago Queiroz de Souza. \\ Andreza Cardoso Ramires \\ Matheus Pantoja de Souza \\ Oseani da Rocha Sena \\ Altair Seabra de Farias \\ Vinícius Azevedo Machado
} E-mail do autor correspondente: tqs.enf17@uea.edu.br

Introdução: Este relato de experiência apresenta as ações do projeto de extensão "Estratégias Educativas em Saúde para adolescentes vivendo com HIV/AIDS": uma parceria entre a Casa Vhida e a UEA", que originou-se de uma atividade de campo realizada por acadêmicos do Curso de Bacharelado em Enfermagem da ESA/UEA. Tais ações delinearam-se a partir do diálogo com profissionais que acompanham os adolescentes assistidos pela Casa Vhida, cuja missão é oferecer a eles uma boa qualidade de vida por meio da assistência médica, social, psicológica e da preservação dos laços familiares. Objetivo: Relatar a experiência dos acadêmicos nas ações educativas de promoção da saúde com os adolescentes assistidos pela Casa Vhida. Metodologia: Os acadêmicos apoiam as ações educativas realizadas pela Casa Vhida por meio do desenvolvimento de oficinas pedagógicas mensais sobre os temas IST/Aids, uso dos medicamentos ARV, sexualidade, gravidez na adolescência, métodos contraceptivos e drogas; elaboram ferramentas didáticas - tais como roda de conversa, dinâmicas lúdicopedagógicas, jogos, expressões artísticas, entre outras - apropriadas às ações educativas voltadas para adolescentes que vivem com HIV/AIDS. São previstas duas etapas para a produção de cada uma das oficinas pedagógicas: a) o planejamento didático da ação educativa e b) a sua execução. Ambas as etapas se dão em conjunto com os profissionais da Casa Vhida, tendo como base a reflexão coletiva sobre os saberes cotidianos e as necessidades de conhecimento dos adolescentes. Resultados: Esperamos ampliar o conhecimento dos adolescentes sobre os temas abordados pelas Oficinas Pedagógicas; instrumentalizar os adolescentes para o autocuidado; aumentar a adesão dos adolescentes que fazem uso da terapia antirretroviral ao acompanhamento realizado pela Casa Vhida. Até o momento, foi possível notar um aumento do interesse dos adolescentes nas oficinas e rodas de conversa pois, gradualmente, a participação voluntária e a quantidade de participantes se elevaram. A aproximação entre os acadêmicos e os adolescentes, através das dinâmicas lúdico-pedagógicas e dos jogos, possibilitou conversar abertamente sobre assuntos como sexualidade, métodos contraceptivos e gravidez na adolescência. Observamos que, entre os acadêmicos e os adolescentes, se firmaram laços de confiança que permitiram aos adolescentes apresentarem situações delicadas e dúvidas a respeito de suas vivências. Percebemos ainda que, além do conteúdo, as oficinas têm contribuído para desenvolver nos adolescentes a habilidade de se expressar em público por meio da fala e da criatividade artística. Contribuições para a Enfermagem: É possível destacar a importância da educação em saúde para instrumentalizar os adolescentes para o autocuidado, para apoiar os trabalhos da Casa Vhida com os adolescentes - no sentido de 
ampliar as condições de desenvolver sua qualidade de vida e, também, para capacitar os acadêmicos de enfermagem.

\section{Referências:}

1. GUEDES, HHS; STEPHAN-SOUZA, AI. A Educação em Saúde como aporte estratégico nas práticas de saúde voltadas ao HIV/Aids: o papel da equipe de saúde. Rev. APS, v. 12, n. 4, p. 388-397, out./dez. 2009.

2. MINISTÉRIO DA SAÚDE - Secretaria de Vigilância em Saúde. Boletim Epidemiológico 2017/HIV e AIDS. Departamento de Vigilância, Prevenção e Controle das Infecções Sexualmente Transmissíveis, do HIV/AIDS e das Hepatites Virais.

3. NASCIMENTO, MS; SANTOS, FPA; RODRIGUES, VP; NERY, VAS. Oficinas Pedagógicas: construindo estratégias para a ação docente - Relato de Experiência. Rev. Saúde. Com 2007; 3(1):85-95.

4. SEIDL, EMF; ROSSI, WS; VIANA, KF; MENESES, AKF; MEIRELES, E. Crianças e Adolescentes vivendo com HIV/Aids e suas famílias: aspectos psicossociais e enfrentamento. Psicologia: Teoria e Pesquisa. set-dez 2005, vol. 21 n. 3, pp. 279-288.

5. SILVA, AFC; CUETO, M. HIV/AIDS, os estigmas e a história. Hist. cienc. saúde-Manguinhos vol.25 no.2 Rio de Janeiro abr.jun. 2018.

Descritores: HIV, Adolescente, Educação em Saúde 


\title{
A PERCEPÇÃO DE ACADÊMICAS DE ENFERMAGEM DIANTE DAS PRÁTICAS ASSISTENCIAIS NO PERÍODO PÓS-OPERATÓRIO EM UMA ENFERMARIA CIRÚRGICA: RELATO DE EXPERIÊNCIA
}

\author{
Leila Gomes Matos Torres \\ Eunice Beatriz Ribeiro Bastos \\ Lenina Jordana Bastos de Macedo \\ Nany Camilla SevalhoAzuelo \\ Eidie do Vale Souza \\ E-mail do autor correspondente:lgmt.enf@uea.edu.br
}

Introdução: No período transoperatório, o enfermeiro é o responsável por executar o levantamento de dados do paciente, implementar as prescrições de enfermagem e avaliar os efeitos destas, ocupando tanto a posição de coordenador quanto de enfermeiro assistencial. ${ }^{(1)} \mathrm{O}$ pós-operatório requer da equipe de saúde uma assistência contínua e de qualidade, sendo os profissionais da equipe de enfermagem os que compõem a maior parte desta equipe. ${ }^{(2)}$ Neste contexto, a qualidade da assistência de enfermagem no pósoperatório deve ser trabalhada tal como sua importância durante a graduação, através de embasamento teórico e experiências durante os estágios. Objetivos: Compartilhar os sentimentos e dificuldades de um grupo de alunas do $6^{\circ}$ período de enfermagem diante das aulas práticas realizadas em uma enfermaria cirúrgica. Metodologia: Trata-se de um relato de experiência descritivo, desenvolvido em um hospital do município de Manaus/AM. A vivência ocorreu no mês de maio de 2018, durante as aulas práticas da disciplina Enfermagem Cirúrgica no Processo de Cuidar da Saúde do Adulto e Idoso. Resultados: A prática na área da enfermagem cirúrgica gerou grandes expectativas ao grupo e, apesar de ser o primeiro contato com este campo, já era sabido que haveria dificuldade de articular a prática com a teoria aprendida em sala de aula, visto a falta de oferta de materiais necessários, ambiente favorável para realização de alguns procedimentos e interação multiprofissional. A priori, houve o reconhecimento do ambiente e apresentação à equipe do setor; a partir disso, iniciamos os procedimentos como: anamnese e exame físico, realização de testes de índice de glicemia capilar, troca de curativos e troca de drenos, sendo este último o que gerou mais ansiedade entre os alunos, pois era um procedimento que ainda não havíamos realizado em outras práticas. Apesar de já ter tido contato com a realização e troca de curativos em lesões cutâneas, a experiência de realizar este procedimento em feridas cirúrgicas causava certa tensão devido ao paciente pós-cirúrgico ser mais suscetível a desenvolver infecções e também à grande pressão sentida neste momento pois, os acompanhantes tinham que se retirar da enfermaria e só podiam retornar ao fim dos procedimentos, o que os deixava impacientes devido à demora, já que, enquanto estudantes, levávamos mais tempo para realizar a troca e, em alguns casos, precisávamos da supervisão da preceptora. Quanto aos pacientes, não ocorreu nenhum tipo de intercorrência, pois estes eram colaborativos. A falta de materiais ou a demora da chegada dos mesmos do setor responsável e a falta de comunicação e interação entre os demais profissionais (médicos, enfermeiros e técnicos) também contribuíram para adversidades. Conclusões e implicações para a Enfermagem: Pesquisas realizadas com alunos de graduação em enfermagem, com relação à sua 
formação como pessoa/profissional, revelam que a formação acadêmica está centrada em conhecimento técnico-científico, e que os sentimentos que aparecem durante a trajetória acadêmica resultam das experiências ao longo dela. ${ }^{(3)}$ Para estudantes de enfermagem, cada prática representa um desafio. Sentimentos como ansiedade e medo são considerados normais nestes momentos de aprendizagem e, lidar com outros tipos de obstáculos que independem do nosso desempenho e controle, é mais desafiador ainda. Entretanto, sabe-se que desafios e dificuldades fazem parte da construção do perfil profissional que ocorre durante toda a graduação e, durante a prática relatada, foram vivenciados diversos tipos de contratempos que iam sendo superados com o auxílio da preceptora e do grupo entre si.

\section{Referências:}

1. Lúcia C, Beck C, Goulart CT, Marion R. O papel do enfermeiro no centro cirúrgico na perspectiva de acadêmicas de enfermagem. 2011.

2. Duarte, M; Costa, S; Stipp, C, et al. O cuidado de enfermagem no pós-operatório de cirurgia cardíaca: um estudo de caso, Rio de Janeiro, 2012.

3. Perbone, JC; Carvalho, EC. Sentimentos do estudante de enfermagem em seu primeiro contato com pacientes. 2011.

Descritores: Cuidado de Enfermagem; Enfermagem Perioperatória; Estudantes de Enfermagem 


\section{RELATO DE EXPERIÊNCIA: PLANEJANDO A FAMÍLIA, ESCOLHA DO MÉTODO EFICAZ COM A AJUDA DA ENFERMAGEM DA ATENÇÃO BÁSICA.}

Francineide Silva dos Santos Macedo

Silvia Aparecida da Silva

Noêmia Salviano Rocha da Silva

E-mail do autor correspondente: francyssm@hotmail.com

Introdução: Conforme a Lei $\mathrm{n}^{\circ} 9.263$ de 01/1996, o Planejamento familiar é uma estratégia, tendo as ações voltadas para auxiliar os casais que pretendem ter filhos ou que queiram adiar o crescimento da família ${ }^{1}$. Vai "além da disponibilização de métodos e ações de educação em saúde, necessitando de atenção especial da área de saúde." Objetivo: Conhecer a estratégia antes do início do estágio na atenção primária. Citar e listar os métodos conceptivos e contraceptivos disponibilizados na UBS vinculada ao SUS. Metodologia: Relato de experiência descritivo com abordagem quantitativa, realizado numa Unidade Básica de Saúde em Manaus, os dados foram coletados observando 200 usuários da estratégia planejamento familiar durante estágio curricular I no período de fevereiro a junho de 2018. Os mesmos foram organizados e fundamentados na literatura selecionada, utilizando um SmartArt para mensurar os resultados. Não foi submetido ao CEP e os aspectos ético-legais foram respeitados de acordo com a Resolução 466/12 do Conselho Nacional de Saúde. Resultados: Observou-se que os métodos conceptivos e contraceptivos descritos nos cadernos de atenção básica e no portal da SEMSA: métodos comportamentais; de barreiras ou preservativos masculinos e femininos; hormonais oral, injetável e emergencial; definitivos: vasectomia e laqueadura são disponibilizados aos usuários mediante procura nas unidades. Durante período de estágio, o método de Barreira preservativo masculino foi o mais utilizado com 48\%, devido ao acesso ser livre nas farmácias das unidades; com $30 \%$ o método hormonal oral e injetável, disponibilizados mediante receita do Enfermeiro ou Médico; os métodos definitivos com $20 \%$ de procura, sendo que os usuários são encaminhados às unidades hospitalares de referência em Manaus; e, com 2\%, os Métodos Comportamentais. Conclusões e contribuições ou implicações para a Enfermagem: Por essas variáveis, se faz necessário o acadêmico ter conhecimento quanto aos métodos disponibilizados na estratégia. O (A) enfermeiro (a) é responsável por planejar, educar, orientar e acompanhar o desenvolvimento da estratégia e, por se tratar de um método gratuito, o planejamento familiar é disponibilizado nas unidades de atenção básica de saúde/ UBS e suas ações são desenvolvidas em conjunto entre o enfermeiro e os casais que procuram as unidades. Após a escolha do melhor método para o casal, o profissional de enfermagem, através do acolhimento, realiza as orientações necessárias para o desenvolvimento e continuidade do método escolhido, garantindo eficácia no planejamento familiar.

\section{Referências:}

1. BRASIL - Ministério da Justiça. Lei $\mathbf{n}^{0}$ 9.263, 12 de janeiro de 1996. Disponível em:<http://www.planalto.gov.br/ccivil_03/leis/L9263.htm> Acesso em: 27 de abril 2018.

2. FERREIRA, R. V.; et al. Planejamento Familiar: gênero e significados. Textos \& Contextos (Porto Alegre), v. 13, n. 2, p. 387 - 397, jul./dez. 2014. Disponível 
em: <DOI: http:// dx.doi.org/10.15448/1677-9509.2014.2.17277> Acesso em: 29 de abr. de 2018.

3. SEMSA - Secretaria Municipal de Saúde. Saúde da Mulher. Disponível em: <http://semsa. manaus.am.gov.br/programas-de-saude/saude-damulher/> Acesso em: 27 de abril 2018.

4. BRASIL. Ministério da Saúde. Secretaria de Atenção à Saúde. Departamento de Atenção Básica. Saúde sexual e saúde reprodutiva - Brasília: Ministério da Saúde, 2010. 300 p.: il. - (Série A. Normas e Manuais Técnicos) (Cadernos de Atenção Básica, n. 26) ISBN 978-85-334-1698-7. Disponível em: <http://bvsms.saude.gov.br/bvs/publicacoes/saude_sexual_saude_reprodutiva.pdf >. Acesso em: 29 de abr. de 2018.

Descritores: Planejamento Familiar; Saúde da mulher; Atenção Básica. 


\title{
O BRINQUEDO TERAPÊUTICO NO AMBIENTE HOSPITALAR
}

\author{
Bruno dos Santos Araújo \\ Handerson da Silva Pereira \\ Fabiane Veloso Soares \\ E-mail do autor correspondente:brunaosantostbt@hotmail.com
}

Introdução: Em crianças hospitalizadas e até mesmo em tratamento de doenças crônicas, o brinquedo apresenta uma possibilidade de comunicação e um alívio para as tensões impostas pela doença e pela própria hospitalização. Isso dá ao enfermeiro meios para traçar metas de assistência de enfermagem. Por isso, orienta-se o uso do brinquedo terapêutico (BT) que se fundamenta nas funções de consciência reprimida da brincadeira e aplica princípios da ludoterapia ${ }^{(1)}$. O Conselho Federal de Enfermagem, por meio da Resolução no 295/2004, dispõe que compete ao enfermeiro que atua na área pediátrica, enquanto integrante da equipe multiprofissional de saúde, a utilização da técnica do brinquedo/brinquedo terapêutico, na assistência à criança e família hospitalizadas ${ }^{(2)}$. Vale ressaltar que, apesar da importância da temática para a promoção da saúde na pediatria, ainda existem acadêmicos, profissionais e hospitais que não utilizam essa estratégia de cuidado para o público infantil, visto que priorizam apenas uma visão limitada aos procedimentos, medicações e técnicas a serem realizadas, mesmo com as legislações em vigência. Objetivo: Relatar a vivência com o lúdico na assistência às crianças hospitalizadas. Metodologia: Trata-se de um relato de experiência, realizado no período de maio a dezembro de 2017, onde acadêmicos de enfermagem passam a ser personagens lúdicas na figura do palhaço. Utilizou-se o método de observação, no qual o indivíduo participa e mantém um elevado grau de contato e envolvimento com os sujeitos, penetrando em grupo o ambiente compartilhando suas experiências ${ }^{(3)}$, obtendo uma melhor contribuição para descrição dos fatos. Resultados: Através do brinquedo terapêutico constatou-se uma visão diferenciada das crianças e dos familiares a respeito dos procedimentos hospitalares, acarretando uma importância significativa do lúdico e, com isso, ocasionando uma melhor aceitação da assistência de enfermagem, mantendo a criança mais tranquila, desviando o foco da dor, tendo a capacidade de amenizar por um momento a situação real em que se encontram através das brincadeiras e atividades. O BT ajuda na adesão aos procedimentos tanto do acompanhante quanto da criança, possuindo um resultado mais rápido no tratamento. Conclusões e implicações para a Enfermagem: O BT proporciona à criança hospitalizada interagir com o ambiente hospitalar, expressar os seus sentimentos, fornecer recursos para a assistência humanizada, além de promover a individualização do cuidado e auxiliar a criança a entender e enfrentar o processo da hospitalização. Considera-se que, através desse relato, se possa ter uma sensibilização dos acadêmicos e da equipe de enfermagem quanto à importância do BT como intervenção para pediatria no defrontamento da hospitalização, obtendo assim os benefícios de sua aplicação.

\section{REFERÊNCIAS:}

1. Melo LL, Valle ERM. Brinquedoteca hospitalar. In: Almeida FA, Sabatés AL. Enfermagem pediátrica: a criança, o adolescente e sua família no hospital. São Paulo: Manole; 2008 p.57-64. 
2. Conselho Federal de Enfermagem. Resolução COFEN n. 295/2004, de 24 de outubro de 2004. Dispõe sobre a utilização da técnica do brinquedo/brinquedo terapêutico pelo enfermeiro na assistência à criança hospitalizada [Internet]. Rio de Janeiro: COFEN; 2004. [citado 2018 SET 27]. Disponível em: http://www.cofen.gov.br/resoluocofen-2952004_4331.html.

3. Figueiredo, Nébia Maria Almeida de. Método e Metodologia na Pesquisa Científica. 3ed. Yendis, 2008.

Descritores:Ludoterapia; Criança; Hospital. 


\title{
O ENFERMEIRO COMO INTEGRANTE FUNDAMENTAL NA DEFESA DO SISTEMA ÚNICO DE SAÚDE SUS: UM RELATO DE EXPERIÊNCIA
}

\author{
Giovana Nogueira Torres \\ Hugo Nepomuceno da Rocha \\ Luana da Silva Praia \\ Victor Nei Vasconcelos Monteiro \\ Sibele Naiara Ferreira Germano \\ E-mail do autor correspondente:gnt.enf17@uea.edu.br
}

Introdução: O Brasil possui um sistema único de saúde para atender toda sua população e o enfermeiro faz parte essencial desse processo porque ele está presente principalmente na assistência direta à população, na gestão, pesquisa, bem como faz parte do controle social por ser usuário. O controle social se refere à participação da comunidade no processo decisório sobre políticas públicas e gestão do SUS ${ }^{1}$. A participação popular na gestão da saúde é prevista pela Constituição Federal de 1998, em seu artigo 198, que trata das diretrizes do SUS: descentralização, integralidade e a participação da comunidade. Em 2006, foi publicado o Pacto pela Saúde que inclui o Pacto em Defesa do SUS, voltado para a participação social ${ }^{2}$. Assim, surge o enfermeiro como peça fundamental na educação popular em saúde para levar os conhecimentos aos usuários sobre o SUS. Desta forma, o projeto de extensão Fortalecendo Vínculos entre Usuários e Profissionais de Saúde em Defesa do SUS, possibilitou que os acadêmicos de enfermagem levassem informações a respeito do Sistema Único de Saúde para a comunidade. Objetivo: Relatar a experiência vivenciada no Programa de Atividade Curricular de Extensão Acadêmica (PACE) em defesa do SUS. Metodologia: Trata-se de um relato de experiência dos acadêmicos da Universidade Estadual do Amazonas (UEA) e Universidade Federal do Amazonas (UFAM), vivenciado durante o projeto de extensão da UFAM, intitulado "Fortalecendo vínculos entre usuários e profissionais da saúde em defesa do SUS". As atividades ocorreram no período de 27 de março a 31 de julho de 2018 nas escolas, Unidades Básicas de Saúde (UBS) e Estratégia Saúde da Família (ESF) e no Programa de Atenção à Saúde do Idoso (PROASI) da UFAM, envolvendo palestras e rodas de conversa sobre diversos temas relativos à saúde, aos direitos e à participação dos usuários no SUS. Resultados: Foram desenvolvidas atividades de educação popular em saúde para estimular a participação da sociedade e profissionais do SUS no controle social. A enfermagem teve um papel especial nessas ações devido a sua importância no processo de promoção da saúde e educação em saúde, dispondo de palestras, folders e rodas de conversas com os participantes por intermédio dos discentes. Durante as ações, foi perceptível para os discentes que muitas pessoas ainda não tinham ciência dos seus direitos ou até mesmo não sabiam onde ir para cobrá-los e exercer sua cidadania. Vale ressaltar que o acesso a uma informação de confiança é capaz de mudar positivamente a realidade de muitos usuários. Conclusão: $O$ enfermeiro se torna peça fundamental em defesa do SUS porque tem a possibilidade de mobilizar a comunidade usando a educação popular em saúde, assegurando que a mesma esteja instruída sobre os seus direitos e as suas possibilidades de garanti-los, porque acreditamos que só lutamos e exigimos aquilo que conhecemos. Assim, o vínculo entre usuários e profissionais é a porta de entrada para o fortalecimento de um sistema que respeite e ofereça um serviço humanizado. 


\section{REFERÊNCIAS}

1. Arantes CIS, Mesquita CC, Machado MLT, Ogata MN. O Controle Social no Sistema Único de Saúde: concepções e ações de enfermeiras da atenção básica. Texto \& Contexto Enfermagem. Florianópolis. 2007; 16(3); 470-8.

2. Rolim LB, Cruz RSBLCC, Sampaio KJAJ. Participação popular e o controle social como diretriz do SUS: uma revisão narrativa. Saúde Debate. 2013; 37 (96); 139-147.

Descritores: Enfermagem, Controle social e Sistema único de saúde. 


\title{
PERCEPÇÃO DE ACADÊMICOS DE ENFERMAGEM NA EMERGÊNCIA DE UM HOSPITAL PÚBLICO NO INTERIOR DO AMAZONAS: UM RELATO DE EXPERIÊNCIA
}

\author{
Alice Lima Macedo \\ Carolinne Amaral Medeiros \\ Railton da Silva Miranda \\ Robson de Oliveira Felix \\ Sthefany da Silva Pinheiro \\ E-mail do autor correspondente:alicemaceda7@gmail.com
}

Introdução: A emergência hospitalar é um ambiente destinado ao atendimento mais adequado à reversão ou estabilização de quadro clínico de pacientes com risco de morte. O sistema de emergência na saúde pública tem grande dificuldade na resolubilidade no atendimento, devido à procura do serviço ser imediato. $\mathrm{O}$ tempo gasto nas consultas de baixa complexidade influencia na agilidade do sistema, ou seja, resultados positivos poderiam ser tratados na atenção básica ${ }^{1}$. Objetivo: Relatar a experiência vivida por acadêmicos de enfermagem na emergência de um hospital público do interior do Amazonas. Metodologia: Trata-se de um estudo descritivo, de caráter narrativo, do tipo relato de experiência, acerca da percepção de acadêmicos de enfermagem da Universidade Nilton Lins, no Hospital público Lazaro Reis, no município de Manacapuru-AM, por meio da observação dos fluxos de atendidos, com classificação por ordem de chegada, no período do mês de julho de 2018. Resultados: No setor de emergência no hospital público, percebeu-se uma grande procura pelos atendimentos de emergência. Em grande parte, não se configuravam como um atendimento que necessitaria prontamente de uma avaliação e resolução rápida do problema. Durante todo o fluxo de atendimento, foi possível observar que muito dos casos não era emergente, como por exemplo, quadros gripais, dor de ouvido, procedimentos de enfermagem (curativo), etc. Todo esse fluxo inapropriado acometia o sistema de pronto atendimento, uma vez que os casos mais emergentes eram atendidos juntamente com aqueles que poderiam esperar um tempo maior, os quais poderiam ser resolvidos na atenção primária. A falta de um instrumento de classificação no Hospital de emergência é um ponto essencial na administração dos atendimentos. A classificação permite uma otimização do tempo no atendimento e, consequentemente, dá prioridade aos casos mais graves e propensos a riscos ${ }^{2}$. Conclusões e contribuições ou implicações para a enfermagem: De acordo com as observações obtidas, faz-se necessário que a equipe multiprofissional crie ou se adeque aos protocolos de urgência e emergência e na segurança do paciente, para que ocorra a padronização do cuidado e triagem dos pacientes, evitando assim, o excesso de pacientes, a demora no atendimento e a má avaliação feita pelos mesmos. Portanto, observou-se a importância do Sistema Manchester de Classificação de Risco no atendimento de emergência no hospital do município de Manacapuru, visando à melhora nos cuidados prestados e priorizando os casos em que há complicações mais severas, ou até mesmo, risco de vida, uma vez que os atendimentos inapropriados para esses serviços congestionam o sistema de pronto atendimento. 


\section{Referências:}
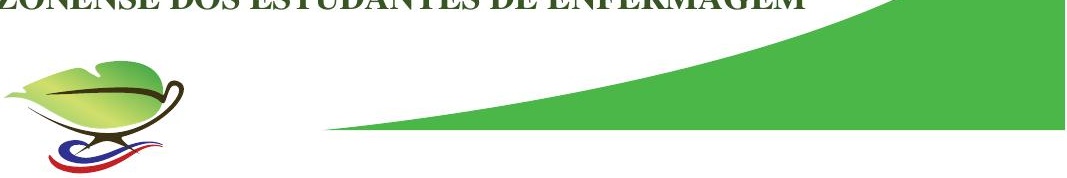

1. Bellucci Júnior JA, Matsuda LM, Marcon SS.Análise do fluxo de atendimento de serviço hospitalar de emergência: estudo de caso. Rev. Eletr. Enf. [Internet]. 2015 jan./mar.;17(1):108-16.

2. Anziliero F, Dal Soler BE, Silva BA, Beghetto MG. Sistema Manchester: tempo empregado na classificação de risco e prioridade para atendimento em uma emergência. Rev Gaúcha Enferm. 2016 dez;37(4):e64753

Descritores: Hospital; emergência; enfermagem. 


\title{
A UTILIZAÇÃO DOS MÉTODOS NÃO FARMACOLÓGICOS PELO ENFERMEIRO OBSTETRA, PARA ALÍVIO DA DOR DURANTE O TRABALHO DE PARTO, EM MATERNIDADES PÚBLICAS DO BRASIL
}

\author{
$\underline{\text { Karla Karoline Nascimento Alencar }}$ \\ Michelle Mota da Silva \\ Fabiane Veloso Soares \\ E-mail do autor correspondente: karla.k.alencar@hotmail.com
}

Introdução: O parto representa um fenômeno único na reprodução humana por envolver aspectos sociais, culturais, econômicos e biológicos ${ }^{1}$. Por este motivo, a experiência vivenciada pela mulher no parto, pode mudar o conceito de parturição. A satisfação da mulher com o parto não está relacionada à ausência da dor. ${ }^{2} \mathrm{O}$ enfermeiro e os profissionais envolvidos neste processo devem proporcionar um cuidado diferenciado e humanizado, tendo em vista que a mulher deve ser protagonista do seu parto ${ }^{1}$. Objetivo: Descrever os principais métodos não farmacológicos, contidos na literatura, utilizados por enfermeiros obstetras no alívio da dor, durante o trabalho de parto, em maternidades públicas no Brasil. Metodologia: Pesquisa de revisão integrativa da literatura, realizada a partir da coleta nas bases de dados eletrônicos BDENF, SCIELO e LILACS. Foram selecionados os artigos em língua portuguesa, disponíveis online, período superior a 2012, e foram excluídas da pesquisa publicações que não apresentassem relação direta com o tema, resumos, trabalhos de conclusão de curso, dissertações, teses e monografias, orientados pelas palavras-chave: parto, humanização, obstetrícia. Resultados e discussões: Foram identificados um total de 90 artigos que, após a aplicação dos critérios de inclusão e exclusão, resultou em uma amostra final de 24 artigos para análise e discussão da pesquisa. Nas pesquisas analisadas, a hidroterapia, bola suíça, massagem, deambulação, mudança de posição e exercício respiratório, foram os mais utilizados, segundo os autores, seguidos da musicoterapia e técnica de rebozo. A hidroterapia usada através da imersão ou banho de aspersão, tem se mostrado bastante efetiva, pois possui baixo custo, é livre de efeitos colaterais e é de fácil aplicabilidade. A temperatura da água recomendada varia de 37 a $38^{\circ} \mathrm{C}$. Além disso, esta técnica deve ser aplicada na fase ativa do trabalho de parto, sendo recomendada a utilização do método durante aproximadamente 20 minutos. $^{3}$ A bola suíça fortalece a musculatura pélvica, exercita os músculos do assoalho pélvico, levantador do ânus, pubococcígeo e da fáscia pélvica, proporciona a adesão de postura vertical ou sentada à mulher e livre movimentação. ${ }^{4}$ Outro método a ser citado é a massagem, que é fundamental para a redução de tensões e desconforto provocados pela dor do trabalho de parto, além da musicoterapia, que serve de instrumento lúdico e promove um estímulo agradável ao corpo. ${ }^{5} \mathrm{O}$ exercício respiratório, na fase ativa do trabalho de parto (dilatação $>4 \mathrm{~cm}$ ), reduz a dor, estresse e ansiedade, através do relaxamento muscular e melhoria da oxigenação materno-fetal. Em relação à deambulação e mudança de posição, as mesmas são positivas, pois servem de distração e aumentam as contrações e dilatação cervical. ${ }^{4}$ A técnica de rebozo consiste em um exercício pouco utilizado, mas de fácil aplicabilidade e baixo custo. Consiste em um xale envolvido na parturiente para alongamento da pelve durante as contrações, para diminuição das dores lombares e promoção do relaxamento muscular. ${ }^{5}$ Conclusões e 
contribuições: Atualmente, os métodos não farmacológicos são indispensáveis na promoção do parto humanizado, pois estes diminuem a quantidade de intervenções e devolvem a autonomia à mulher. Para isso, é indispensável verificar quais os métodos a serem aplicados durante o parto e seus benefícios, para que ocorra um avanço na qualidade assistencial, e reconhecer que o enfermeiro é indispensável no uso destes métodos, pois este possui conhecimentos científicos que possibilitam maior eficácia quando aplicados de forma correta.

\section{Referências:}

1. Reis TLR, Padoim SMM, Toebe TRP, Paula CC, Quadros JS. Autonomia feminina no processo de parto e nascimento: revisão integrativa da literatura. Rev. Gaúcha de Enfermagem. 2017; 38 (1); 1-8.

2. Fujita JALM, Shimo AKK. Parto humanizado: experiências no sistema único de Saúde. Revista Mineira de Enfermagem. 2014 out/dez; 18(4): 1006-10.

3. Silva CA, Lara SRG. Uso do banho de aspersão associado à bola suíça como método de alívio da dor na fase ativa do trabalho de parto. Br J Pain. 2018 abrjun: 1 (2): 167-170.

4. Oliveira LM, Cruz AGC. A utilização da bola suíça na Promoção do Parto Humanizado. Rev. Brasileira de Ciências da Saúde. 2014; 18(2): 175-80.

5. Tupinambá LS, Brito AR, Oliveira LVS, Lopes MMB. Mecanismos não farmacológicos para o controle da dor durante a parturição: uma revisão integrativa. Conbracis. 2017: 1-6. 20.

Descritores: parto; humanização; obstetrícia. 


\title{
O TRANSTORNO DO ESPECTRO DO AUTISMO SOB A PERSPECTIVA DO CUIDADO PÓS REFORMA PSIQUIÁTRICA
}

\author{
Thaise Maia de Souza \\ Amanda Daniely Ramos Correa \\ Sula Francisca França Costa \\ Bianca Jardim Vilhena \\ E-mail do autor correspondente: thaisemaia.tm@gmail.com
}

Introdução: $\mathrm{O}$ autismo é um transtorno caracterizado principalmente por déficits na comunicação social e interação social que foi descrito primeiramente por Leo Kannerem 1943, Onzi e Gomes (2015). No Século XIX, antes de surgir as primeiras pesquisas sobre o autismo, todas as pessoas com transtornos considerados mentais eram institucionalizadas em hospitais psiquiátricos. Hans Asperger era psiquiatra e percebeu que, no meio das pessoas com esquizofrenia, havia pessoas que não eram esquizofrênicas, e percebeu ainda que, no meio dessas pessoas "diferentes", cada uma possuía particularidades especiais. Posteriormente, essas pessoas foram denominadas com transtorno de Asperger, que atualmente é um dos transtornos de desenvolvimento social inclusos no TEA (Transtorno do Espectro do Autismo) Stelzer (2010). Objetivo: Relatar aspectos positivos da reforma psiquiátrica no prognóstico do transtorno do espetro do autismo. Metodologia: Trata-se de um estudo descritivo, do tipo relato de experiência, a partir das visitas técnicas em um espaço de atendimento ao TEA de referência em Manaus no período de abril a maio de 2018. Os profissionais foram observados quanto à forma em que realizam o tratamento a nível de atenção primária da criança com TEA. Resultados e discussão: A reforma psiquiátrica no Brasil trouxe diversas mudanças para o modelo assistencial de saúde mental. Isso acarretou inúmeros benefícios para os usuários, que até então era baseado em institucionalização. Nesse contexto, enquadram-se as pessoas com transtorno do espectro do autismo que, antes da reforma psiquiátrica no Brasil, eram mantidas institucionalizadas com outras pessoas portadoras de doenças mentais, passando por tratamentos insalubres, desumanos e por vezes letais. Segundo Schmidt (2013), o autismo não é uma doença, é um distúrbio neurológico caracterizado por dificuldades sociocomunicativas, mas somente em 1993, a síndrome foi adicionada ao CID 10. O espaço de atendimento à criança com TEA que visitamos, é um Centro de referência de Manaus, que tem como objetivo atender integralmente, a nível de atenção primária, as pessoas com diagnóstico de TEA e /ou quem não tem diagnóstico. Observamos, durante as visitas, que o espaço proporciona liberdade e interação para as crianças. Isso ajuda a desestigmatizar qualquer semelhança com um ambiente hospitalar. O tratamento ofertado consiste em orientar a família na promoção da autonomia e interação das crianças com autismo, bem como ofertar serviços de psicologia, fonoterapia, terapia ocupacional, psiquiatria, neurologia pediátrica, odontologia, enfermagem, nutrição, serviço social, pedagogia, psicopedagogia e educação física, facilitando o alcance do prognóstico da pessoa com TEA. Onzi e Gomes (2015) corroboram outros estudos quando dizem que o tratamento adequado ajuda a atenuar déficits e facilita o cuidado à criança com TEA. Conclusões: Os dados encontrados são de grande importância, uma vez que podemos compreender as dimensões entre os males do modelo manicomial e os benefícios da reforma psiquiátrica no diagnóstico e tratamento do TEA. Além disso, as informações prestadas aos acadêmicos de enfermagem durante a exposição do trabalho possibilitou uma nova visão acerca do 
cuidado em saúde mental, evidenciando que o mais importante não é curar, e sim mostrar para a sociedade que é possível conviver com as diferenças.

\section{Referências:}

1. Berlinck MT, Magtaz AC, Teixeira M. A Reforma psiquiátrica brasileira: perspectivas e problemas. Ver Latinoam, São Paulo, 2008a; 11(1): 21-27.

2. Oliveira KG, Sertié AL. Transtornos do espectro autista: um guia atualizado para aconselhamento genético. Eistein, 2017.

3. Onzi FZ, Gomes RF. Transtorno do espectro autista: a importância do diagnóstico e reabilitação. Caderno pedagógico, 2015.

Descritores: Reforma psiquiátrica, desinstitucionalização, TEA. 


\title{
RELATO DE EXPERIÊNCIA: A IMPORTÂNCIA DO ACOLHIMENTO E ORIENTAÇÃO PARA A COLETA DO EXAME PAPANICOLAU
}

\author{
$\underline{\text { Silvia Aparecida da Silva }}$ \\ Francineide Silva dos Santos Macedo \\ Noêmia Salviano Rocha da Silva \\ E-mail do autor correspondente: silvia_ap.silvia@hotmail.com
}

Introdução: O nome "Papanicolau" é uma homenagem ao criador do método para coleta do material ginecológico: o patologista Georges Papanicolau ${ }^{1}$. É um exame considerado um instrumento para o rastreio e diagnóstico do câncer de colo de útero precoce ${ }^{2}$. Objetivos: Relatar a experiência durante o estágio supervisionado na atenção básica de saúde, durante acolhimento do exame Papanicolau, e mostrar o impacto de um bom acolhimento às usuárias. Metodologia: $O$ presente estudo foi do tipo retrospectivo, descritivo e quantitativo. Realizou-se o registro de informações existentes a partir das anotações das acadêmicas. Foram selecionados artigos conforme os descritores e anotações das acadêmicas durante o estágio na Unidade Básica de Saúde. Os dados foram retirados das anotações de estágio em Atenção Básica das acadêmicas no período de fevereiro a junho de 2018. Os dados foram analisados através do programa Microsoft Excel, com formulação de tabela para mensuração dos resultados. Por se tratar de uma revisão para embasar a experiência acadêmica, o estudo não foi submetido à avaliação do comitê de ética em pesquisa, de acordo com a Resolução 466/12 do Conselho Nacional de Saúde, porém todos os preceitos éticos estabelecidos foram respeitados no que se refere a zelar pela legitimidade, privacidade e sigilo das informações, citando todos os autores dos artigos selecionados. Resultados: $\mathrm{O}$ acolhimento é um vínculo entre o usuário e o serviço de saúde, com a resolubilidade do atendimento e com a adequação do serviço às suas necessidades ${ }^{3}$. A necessidade de melhor preparo, para a realização desta atividade, chamou a atenção das acadêmicas. Nesse momento, as usuárias são acolhidas e orientadas quanto ao procedimento a ser realizado. Durante os estágios, foram acolhidas 120 usuárias na sala ginecológica, $45 \%$ nunca haviam feito o preventivo; $75 \%$ desconheciam o Kit utilizado para exame, $90 \%$ gostaram da dinâmica utilizada, voltada em apresentar o material e a técnica usada para coleta, e 10\% não opinaram. Conclusões e contribuições ou implicações para a Enfermagem: Diante da importância da realização do exame Papanicolau, surge a necessidade de requerer maior preparo teórico dos acadêmicos de enfermagem quanto à abordagem das usuárias na atenção básica durante o acolhimento, e orientação antes da realização do exame de preventivo. Haja vista que o mesmo exige de quem o realiza uma postura ética, que implica na escuta do usuário em suas queixas, no reconhecimento do problema existente, no processo de saúde e adoecimento, e na responsabilização pela resolução, com ativação de redes de compartilhamento de saberes. Concluindo, consideramos que a capacitação de alguns acadêmicos durante a vida acadêmica para atuação no período de estágio, apresenta um déficit que pode comprometer a forma de acolher as usuárias das unidades de saúde. 


\section{Referências:}

1. Dicas em Saúde. Exame preventivo do câncer de colo uterino (Papanicolau). BVS-Ministério da $\quad 2011 . \quad$ Saúde. Disponível: <bvsms.saude.gov.br/bvs/dicas/237_papanicolau. html>.

2. CASTRO, L.F. Exame Papanicolau: o conhecimento das mulheres sobre o preventivo e a estratégia do combate ao câncer de colo de útero. Rev. Eletrônica da Disponível: $<$ https://www.nescon.medicina.ufmg.br/biblioteca/imagem/2318.pdf $>$ Acesso: 01/05/2018.

3. GUERRERO, P. et al. $\mathrm{O}$ acolhimento como boa prática na atenção básica à saúde. Texto contexto - enferm. Florianópolis, v.22, n.1, p.132-140, Mar. 2013. Disponível:<http://dx.doi. $\quad$ org/10.1590/S010407072013000100016>Acesso: 05/05/2018.

Descritores: Papanicolau; Acolhimento; Atenção Básica. 


\title{
TERAPIA COMUNITÁRIA INTEGRATIVA: UMA METODOLOGIA DE PROMOÇÃO DE SAÚDE MENTAL EM UM CENTRO DE ATENÇÃO PSICOSSOCIAL DA CIDADE DE MANAUS
}

\author{
$\underline{\text { Isabelle Vasconcelos de Sousa }}$ \\ Bruna Amora Guedes \\ Flávia Braga Huamanculi \\ Nailu Flor Chenini \\ Samuel Lima Ferreira \\ Alaidistania Aparecida Ferreira
}

E-mail do autor correspondente: isavasconcelosds@gmail.com

Introdução: A Terapia Comunitária Integrativa (TCI) é uma ferramenta utilizada para dar voz aos participantes, com a oportunidade de relatar suas opiniões e anseios, tendo a certeza de que serão ouvidos. Realizada através de $\mathrm{x}$ etapas, a TCI propõe aos participantes a superação através do enfrentamento das situações por eles apresentadas, onde todos têm liberdade para falar e um momento para ouvir. Essa terapia é benéfica no processo de reintegração desses usuários ao convívio social, uma vez que as relações humanas foram desequilibradas por problemas sociais como o alcoolismo e uso de substâncias ilícitas. Objetivos: Relatar a experiência de acadêmicos durante observaçãoparticipativa em uma Roda de terapia comunitária, descrevendo-a como metodologia facilitadora para o enfrentamento de demandas e sofrimentos psicossociais de usuários dos Centros de Atenção Psicossocial (CAPS). Metodologia: Trata-se de um relato de experiência através de observação-participativa. Foi realizada roda de terapia comunitária no CAPS Álcool e Drogas Dr $^{\circ}$ Afrânio Soares, com a participação de 14 pacientes, 5 alunos e 1 Enfermeiro com Capacitação em TCI. A TCI consiste em uma metodologia simples de cuidado integral e de pouco custo financeiro, fundamentada sobre cinco pilares: o pensamento sistêmico, a teoria da comunicação, a antropologia cultural, a pedagogia de Paulo Freire e a resiliência. Resultados: Um dos pilares da TCI é a autonomia do sujeito, tendo como objetivo fornecer aos participantes um outro modo de encarar os empecilhos que são encontrados durante a terapêutica, seja problemas familiares e de autoestima. Os usuários podem atingir autopercepção e passam a transformar a sua realidade através da reflexão e problematização. A pedagogia de Paulo Freire, que também é baseada na autonomia do sujeito, propõe que o indivíduo seja o criador de seu conhecimento e o adquira de forma espontânea. Ao término das sessões, os participantes relatam que conquistam outra percepção sobre o problema que os estava acometendo e, agora, eles têm a ideia de potencial para resolução. Conclusões e contribuições ou implicações para a Enfermagem: A TCI como ferramenta educacional, proporciona o poder da autonomia, de forma a ajudar na reabilitação biopsicossocial desse indivíduo, de modo que esse possa vir a participar novamente de ciclos sociais dos quais tinha sido desligado, e tudo isso através do diálogo que é desenvolvido. Sendo assim, a TCI vem a contribuir como uma nova forma de tratamento, de modo a cuidar do paciente e do seu convívio com o meio. 


\section{Referências:}
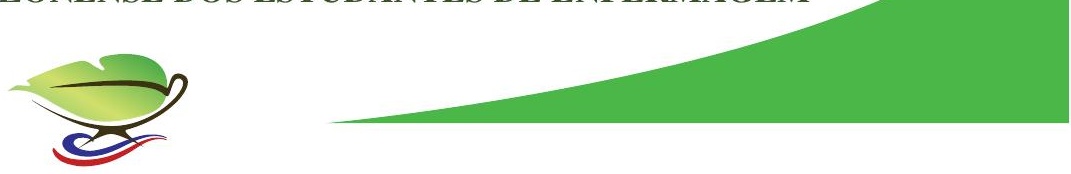

1. CARVAlHO, Mariana Albernaz Pinheiro de et al. Contribuições da terapia comunitária integrativa para usuários dos Centros de Atenção Psicossocial (CAPS): do isolamento à sociabilidade libertadora. Cad. Saúde Pública, Rio de Janeiro , v. 29, n. 10, p. 2028-2038, Oct. 2013. Available from <http://www.scielo.br/scielo.php?script=sci_arttext\&pid=S0102311X2013001000019\&lng=en\&nrm=iso >. access on 15 Oct. 2018.

2. FERREIRA FILHA, Maria de Oliveira et al. A terapia comunitária como estratégia de promoção à saúde mental: o caminho para o empoderamento. Revista Eletrônica de Enfermagem, Goiânia, v. 11, n. 4, p. 96470, dez. 2009. ISSN 1518-1944. Disponível em: <https://www.revistas.ufg.br/fen/article/view/33252>. Acesso em: 15 out. 2018.

Descritores: Terapia; Comunicação; Enfermagem; 


\title{
PERCEPÇÃO DOS ENFERMEIROS SOBRE OS CUIDADOS E PREVENÇÃO DAS ÚLCERAS POR PRESSÃO EM PACIENTES HOSPITALIZADOS
}

\author{
Eunice Beatriz Ribeiro Bastos \\ Flávia Roberta Dias Coelho \\ Maria Luiza Carvalho de Oliveira \\ E-mail do autor correspondente:ebrb.enf@uea.edu.br
}

Introdução: A terminologia Úlcera por Pressão foi modificada para Lesão por Pressão (LPP) e foi atualizada conforme a nomenclatura dos estágios do sistema de classificação pelo National Pressure Ulcer Advisory Panel (NPUAP). ${ }^{(1)}$ Essa condição é um grave problema de saúde pública, pois impacta o sistema e compromete a qualidade de vida da população, elevando os índices de morbimortalidade e as despesas hospitalares. Seus altos índices de incidência e prevalência reforçam a necessidade de uma assistência planejada com ações de prevenção e cuidados da equipe e do enfermeiro responsável pelo cuidar. A lesão por pressão é uma característica definidora quando se fala em integridade da pele prejudicada, acarretando prejuízos significativos ao estado de saúde do indivíduo, pois propicia o risco de infecção local ou sistêmica, uma vez que gera uma porta de entrada para microrganismos oportunistas e infecciosos, podendo até comprometer a vida. ${ }^{(2-4)}$ Objetivo: O estudo teve como objetivo descrever a percepção dos enfermeiros sobre os cuidados e prevenção das lesões por pressão em pacientes hospitalizados. Metodologia: Trata-se de um estudo de campo, descritivo, de cunho qualitativo, realizado no período de 2017 a 2018, utilizando, como fonte de dados, dez enfermeiros da clínica médica de um hospital público de Manaus. Utilizou-se a análise de conteúdo de Bardin para a análise dos dados. Esta pesquisa foi realizada através da participação do programa de apoio à iniciação científica (PAIC/UEA). Resultados: Na realização de ações preventivas de desenvolvimento das lesões por pressão, de acordo com a experiência dos enfermeiros, foram citados materiais pessoais adequados, alimentação balanceada e cuidados profissionais eficientes. Quanto às facilidades para prevenção das lesões, pode-se mencionar a colaboração dos acompanhantes, orientação sobre a lesão por pressão e suas consequências, atividades como a utilização de coxim, colchão caixa de ovo, hidratação da pele, mudança de decúbito e ter recursos humanos suficientes, como o maqueiro na unidade, para a execução dessas ações .Em relação às dificuldades para a prevenção das lesões, estes listaram a falta cumprimento da orientação quanto à mudança de decúbito dos acompanhantes e profissionais, alimentação ineficaz, déficit de materiais específicos e de profissionais devido à demanda de pacientes e ausência de cuidados com o paciente quanto à higiene e hidratação da pele. Os principais cuidados procedidos pelos enfermeiros foram curativos diários, hidratação da pele, massagens, mudança de decúbito a cada 2 horas e utilização de placas preventivas. As facilidades encontradas para a realização do cuidado das lesões foram: quando há uma educação efetiva sobre a lesão por pressão aos pacientes, acompanhantes e profissionais, a realização de curativo diário, hidratação da pele, uso de colchão caixa de ovo e mudança de decúbito. As dificuldades relatadas no cuidado das lesões foram déficit de materiais específicos, cumprir o que é solicitado pelos enfermeiros, colaboração dos pacientes e acompanhantes quanto à mudança de decúbito e lesão prévia à internação na unidade. Conclusões e contribuições 
para a Enfermagem: Tendo em vista os aspectos analisados, os enfermeiros entendem as lesões e sabem lidar com suas particularidades, porém, é necessário haver recursos materiais e profissionais eficientes para possibilitar ações de prevenção e cuidado efetivas quanto à assistência prestada aos pacientes. É importante que a educação permanente seja realizada de forma adequada para que haja uma atualização e reafirmação de conhecimentos que aprimorem os cuidados de enfermagem, assim como a educação em saúde para os pacientes e acompanhantes, pois são métodos que podem ser realizados de forma simples e, mesmo assim, se tornarem eficientes para a prevenção e cuidados aos pacientes.

\section{Referências:}

1. Associação Brasileira de Estomaterapia, 2016.

2. Oliveira, VR de. A importância da prevenção de úlceras por pressão em pacientes acamados - Porto Alegre; s.n; 2014. 14 p.

3. Smeltzer SC, Bare BG, Hinkle JL, Cheever KH. Brunner \& Suddarth: Tratado de Enfermagem Médico-Cirúrgica. 12. ed. Rio de Janeiro: Guanabara Koogan, 2011.

4. Souza NF. Prevenção de úlcera por pressão: um ensaio sobre o olhar clínico de enfermeiras sobre o corpo tegumentar de seus clientes. Rio de Janeiro; s.n; maio 2011. 115p.

Descritores: Enfermagem; Lesão por pressão; Cuidados de Enfermagem. 


\section{RESUMOS}

\section{EIXO 2: ÁREAS DE ATUAÇÃO DOS PROFISSIONAIS DE ENFERMAGEM}

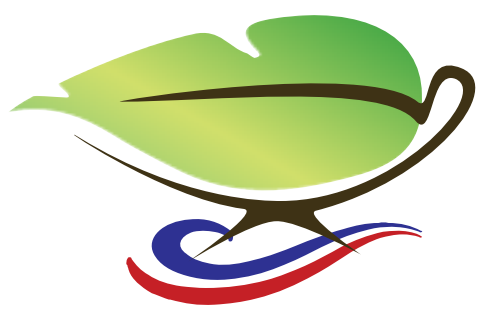




\title{
EDUCAÇÃO EM SAÚDE COMO FERRAMENTA PARA O CUIDADO: UMA EXPERIÊNCIA COM CUIDADORES DE IDOSOS
}

\author{
Mylena Silva de Souza \\ Thayanne Carlos Chaves \\ Daniela Sandy Silva de Souza \\ Luan Augusto Penha de Souza \\ Júlio Cesar Oliveira de Souza \\ Anna Paula de Carvalho \\ E-mail do autor correspondente:mylena.98ss@gmail.com
}

Introdução: Entre os mecanismos mais comumente utilizados na assistência à saúde dos indivíduos, destaca-se a educação em saúde, que permite ao cuidador, seja ele, profissional, ou o familiar, diminuir significativamente as taxas de complicações posteriores relacionadas à saúde do cliente, através da preocupação com as medidas preventivas (MINISTÉRIO DA SAÚDE, 2013). Entretanto, a educação em saúde permite que a ação não seja limitada apenas à transmissão de informações, orientada para a prevenção ou o tratamento da doença, mas abrange também a capacitação dos indivíduos para controlarem os seus próprios determinantes de saúde, através da criação ou do desenvolvimento de competências de ação (FEIO; OLIVEIRA, 2015). Atualmente, os modelos de atenção à saúde da pessoa idosa enfatizam o uso de ferramentas de autocuidado e de planos integrados de cuidado, visto que essa população está sujeita a complicações relacionadas à saúde. De acordo com Ferreti et al. 2013, em uma população de 389 idosos, em média, o número de quedas é de 1,6 $( \pm 0,97)$ ao ano. Assim, a educação em saúde mostra-se uma ferramenta a ser usada em todos os âmbitos do cuidado dessa população, seja na prevenção, terapêutica, reabilitação ou na promoção da saúde. Objetivos: Relatar os processos vivenciados durante a ação educativa dialogada para a equipe cuidadora dos idosos de um abrigo cedido por uma Igreja. Metodologia: Trata-se de um relato de experiência de uma ação educativa que ocorreu no dia 20 de julho de 2017, na sede de um Programa que visa Atenção à Saúde do Idoso, um projeto de extensão de uma Instituição de Ensino Superior, na cidade de Manaus, com o intuito de capacitar os profissionais envolvidos no cuidado de idosos sobre prevenção de quedas. A equipe de cuidadores era composta por psicólogos, cozinheiros, e técnicos de enfermagem. Os acadêmicos foram facilitadores da ação, utilizando ilustrações e conversas informais, apresentaram ações cotidianas no contexto da unidade para evitar quedas e complicações na saúde e no bem-estar dos idosos. Resultados: Durante a apresentação evidenciou-se o interesse do público, devido ao entusiasmo explícito e a correlação explanada com situações de seus cotidianos. Ao se deparar com as ações apresentadas, a maioria do público as denominou "simples". Entretanto, a equipe revelou que não praticava frequentemente. Um participante relatou que, como mostrado durante a atividade, os incidentes com os idosos eram recorrentes, e propôs uma situação-problema. A partir do exposto, foram dadas propostas de como agir no caso de uma queda e maneiras de como evitá-las; foi perceptível que o diálogo se descomplicou, devido à informalidade e aproximação do contexto dos participantes. Além disso, devido a 
requerimentos dos participantes, houve a orientação a respeito dos calçados adequados para evitar quedas na população idosa, evidenciando a busca de ferramentas para prevenção. A participação do público, através de dúvidas, perguntas, e situaçõesproblemas, permitiu que a atividade se transformasse numa transmissão de conhecimentos bidirecional, acarretando informações para ambos os lados. Assim, criouse um ambiente para formulação de mecanismos e estratégias para prevenção de situações que impliquem na saúde dos idosos. Conclusões e contribuições ou implicações para a Enfermagem: A vivência possibilitou novas experiências relacionadas ao uso da educação em saúde e à forma de transmitir informação relacionada ao conteúdo aos envolvidos. Além disso, a execução da atividade possibilitou contato com um público que está diretamente ligado ao cuidado e a importância do papel da enfermagem nessas atividades, visto que é possível realizar prevenção com o intuito de minimizar os problemas de saúde.

\section{Referências:}

1. Ministério da Saúde. Secretaria de Atenção à Saúde. Cadernos de Atenção Básica. Brasília (DF); 2013. [Acesso em:30 de setembro de 2018],n 34.Disponivel: http://189.28.128.100/dab/docs/portaldab/publicacoes/caderno_34.pdf.

2. Feio A, Oliveira CC. Confluências e divergências conceituais em educação em saúde. Saúde e Soc. [online]. 2015, [Acesso em: 30 de setembro 2018] v.24, pp. 703-715. Disponível em: http://www.scielo.br/pdf/sausoc/v24n2/0104-1290-sausoc-24-0200703.pdf.

3. Ferretti, F.; Lunardi, D.; Bruschi, L. Causas e consequências de quedas de idosos em domicílio; Fisioter. Mov., Curitiba, set./dez. 2013 [Acesso em: 28 de setembro 2018] v. 26, n. $4, \quad$ pp. 753-762, Disponível em: http://www.scielo.br/pdf/fm/v26n4/a05v26n4.pdf.

Descritores: Educação em saúde; saúde do idoso; cuidadores. 


\title{
APLICAÇÃO DE ATIVIDADE LÚDICA COMO ESTRATÉGIA NA PROPAGAÇÃO DO SABER E DO CUIDADO DE ENFERMAGEM NA SAÚDE MENTAL: RELATO DE EXPERIÊNCIA
}

\author{
Mirrelly Campos Santos \\ Graziela da Silva Moura \\ Gabriel Bezerra Dias \\ E-mail do autor correspondente:mirrelly@ hotmail.com
}

Introdução: A Rede de Cuidados em Saúde Mental, Crack, Álcool e outras drogas foi pactuada em junho de 2011, através da implantação do Decreto no 7508 de 28 de junho de 2011, e prevê assistência, a partir da Política Nacional de Saúde Mental, prioritariamente por meio de CAPs, Centros de Convivência e Cultura e Unidades de Acolhimento (1). Esses espaços acolhem os doentes, modificando a estrutura da assistência à saúde mental, e vêm substituindo progressivamente o modelo hospitalocêntrico e manicomial, na tentativa de construir um sistema de assistência orientado pelos princípios fundamentais do SUS (2). Essa forma de atendimento é fruto de um longo processo de luta social que culminou com a Reforma Psiquiátrica em 2001. Sua principal bandeira está na mudança do modelo de tratamento (3). Objetivo Geral: Empregar o conhecimento em neuropsiquiatria e vivências em hospital psiquiátrico local, através de atividade lúdica, como estratégia na propagação do saber e do cuidado de enfermagem na saúde mental. Objetivos Específicos: Descrever ações de enfermagem vivenciadas em campo prático, por meio de atividade cênica como instrumento facilitador do aprendizado. Ainda, demonstrar vieses na execução dos serviços de enfermagem, através de atividade lúdica, como possibilidade de estratégia avaliativa. Metodologia: O presente trabalho está inserido no projeto de neuropsiquiatria da instituição de ensino Centro Educacional Literatus e foi desenvolvido a partir de dois momentos: em abordagem inicial, o grupo discente permeou o espaço do hospital psiquiátrico Eduardo Ribeiro, localizado em Manaus, que funciona como pronto-socorro direcionado à reabilitação e/ou internação de indivíduos com transtornos mentais. A prática seguiu com diálogo reflexivo sobre o encontrado no campo prático, supervisionado pela enfermeira docente Graziela Moura, a fim de construir um roteiro cênico para a realização da segunda etapa. Complementando, houve a realização da atividade cine viagem, onde foi apresentado o filme "NISE: $O$ coração da loucura". Baseando-se nessas atividades precursoras, a segunda etapa foi executada com a peça teatral "As duas faces da mente". Construída com uma linguagem cômica, interativa, de fácil entendimento e sem cunho moralizante, abordou-se o desenvolvimento da reforma psiquiátrica no Brasil. Resultados: Considerando-se a estigmatização inicial em relação aos portadores de transtornos mentais, a experiência vivenciada no campo prático e o referencial teórico abordado, através do componente curricular, nota-se que é necessária uma análise pessoal antes da aplicação do cuidado de enfermagem frente aos doentes em crise. Ainda, percebe-se a chance de-como todos estão susceptíveis no enquadramento desta morbidade hereditária, biológica e até mesmo social. Conclusões e contribuições ou implicações para a Enfermagem: A partir das atividades, os discentes envolvidos tiveram a iniciativa de buscar uma estratégia para repaginar a arte do cuidar nesse seguimento (ou segmento??), visando novos hábitos do cuidado de enfermagem e aprimoramento no entendimento frente à saúde mental. Sugere- 
se e conclui-se então, que o conhecimento técnico, associado às vivências e ao ensino dinâmico e inovador, colaboram positivamente na formação transdisciplinar junto ao profissional, ao aluno e à comunidade.

\section{Referências:}

1. Câmara dos Deputados [homepage da internet]. Decreto $n^{\circ} 7508$, de 28 de junho de 2011 [acesso em 24 de Setembro de 2018]. Disponível em: http://www2.camara.leg.br/legin/fed/decret/2011/decreto-7508-28-junho-2011-610868norma-pe.html.

2. Bezerra Junior B. Desafios da Reforma Psiquiátrica no Brasil. Rev. Saúde Coletiva 2007; 17(2): 243-250.

3. Pense SUS [homepage da internet] Saúde mental [acesso em 23 de setembro de 2018]. Disponível em: https://pensesus.fiocruz.br/saude-mental.

Descritores: Serviços de Saúde Mental; Pessoas com Deficiência Mental; Assistência à Saúde Mental. 


\title{
O OLHAR DO ACADÊMICO DE ENFERMAGEM SOBRE A ATUAÇÃO DO ENFERMEIRO NO CENTRO DE PARTO NORMAL INTRA-HOSPITALAR: UM RELATO DE EXPERIENCIA.
}

\author{
Eline Araújo de Oliveira \\ Evelyn Barros de Oliveira \\ Renildo Rodrigues Farias \\ Edson Silva do Nascimento \\ Rodrigues Ferreira de Souza \\ Graciana de Sousa Lopes \\ E-mail do autor correspondente: eline_araujo@ hotmail.com.br
}

Introdução: A Rede Cegonha consiste numa rede de cuidados que visa assegurar à mulher o direito ao planejamento reprodutivo e à atenção humanizada durante a gravidez, ao parto e ao puerpério ${ }^{1}$. O processo de nascimento é historicamente um acontecimento natural, de caráter íntimo e reservado, sendo uma experiência compartilhada entre as mulheres e seus familiares ${ }^{2}$. As práticas humanizadas no nascimento constituem um processo em que o profissional deve preocupar-se com a fisiologia da concepção, não intervindo desnecessariamente, considerando os aspectos sociais e culturais do parto e nascimento, ofertar suporte emocional, informando a parturiente sobre os procedimentos aos quais será submetida, proporcionar ambiente acolhedor e esclarecer suas dúvidas. Essas são condutas essenciais para uma assistência de qualidade ${ }^{3}$. Objetivo: Relatar a importância da atuação do Enfermeiro Obstetra no processo de nascimento, com enfoque no uso das boas práticas no trabalho de parto. Metodologia: Trata-se de uma narrativa conforme uma experiência de graduandos em Enfermagem de uma Instituição de ensino de nível superior, em uma Maternidade pública de referência em Manaus-AM, no período de 02 a 09 de Abril de 2018, durante as aulas práticas da disciplina de saúde da mulher. Resultados: O Centro de Parto Normal Intra-Hospitalar (CPNI) assegura ao Enfermeiro Obstétrico realizar partos normais de risco habitual. Durante o período das aulas práticas, foi observada a assistência às mulheres em trabalho de parto, sendo proporcionado às parturientes, os acompanhantes de sua livre escolha, se estabelecendo um elo de confiança, segurança e tranquilidade, sendo ela a principal protagonista deste processo de parturição e a equipe como facilitadores do processo. Foram utilizadas as boas práticas de atenção ao parto, técnicas de relaxamento e alívio da dor por meios não farmacológicos, como: massagens na região lombo-sacral, exercícios na bola suíça, musicoterapia de escolha da mulher, movimentação da parturiente durante o trabalho de parto, banho morno de aspersão, aromaterapia, exercícios respiratórios e incentivo a adotar qualquer posição que achasse mais confortável incluindo as posições de cócoras, lateral ou quatro apoios no período expulsivo. Realizados também o clampeamento oportuno do cordão umbilical, participação do acompanhante na realização do corte, juramento, contato pele a pele do binômio e incentivo ao aleitamento materno na primeira hora de vida. Conclusões e contribuições ou implicações para a Enfermagem: $O$ enfermeiro desenvolve um papel fundamental na assistência à parturiente, com habilidades de escuta e acolhimento em um evento extremamente sensível para a mesma. Dessa forma, para a Enfermagem, é necessário que haja preocupação em considerar a mulher como um ser 
com particularidades que demanda assistência individualizada e ampliação do olhar a respeito das práticas de cuidado.

\section{Referências:}

1. BRASIL. Ministério da Saúde. Portaria n. 1.459, de 24 junho de 2011. Institui no âmbito do Sistema Único de Saúde - SUS - a Rede Cegonha. Brasília, Diário Oficial da União, 24 de junho de 2011.

2. VELHO, Manuela Beatriz; OLIVEIRA, Maria Emilia de; SANTOS, Evanguelia K. Atherino. Reflexões sobre a assistência de enfermagem prestada à parturiente. REBEn - RevBrasEnferm, Brasília 2010, jul-ago; 63(4): 652-9. Acesso em: 03 out. 2018.

3. PEREIRA, Sinara Santos et al., Parto natural: a atuação do enfermeiro diante da assistência humanizada. Tempus, actas de saúde colet, Brasília, 10(3), 199-213, set, 2016.

Descritores: Parto Humanizado; Enfermagem Obstétrica; Humanização da Assistência. 


\title{
CUIDADOS DE ENFERMAGEM NA ATENÇÃO À PESSOA IDOSA: RELATO DE EXPERIÊNCIA
}

\author{
Núbia Altina de Carvalho Oliveira \\ Camila Carlos Bezerra
}

E-mail do autor correspondente: nbiaaltina@gmail.com

Introdução: O Brasil e o mundo estão envelhecendo. Nas próximas décadas, a população mundial com mais de 60 anos vai passar dos atuais 841 milhões para 2 bilhões até 2050. [1] Em 2014, os idosos já representavam 13,7\% da população brasileira. Em 2050, calcula-se que esse número chegue a 64 milhões. ${ }^{[2]}$ Com o aumento do envelhecimento populacional, há uma crescente necessidade de se investigar indicadores que contribuem e interferem no que se refere à qualidade de vida dessa população, bem como possíveis intervenções para atender essas necessidades. ${ }^{[3]}$ Os cuidados de enfermagem são de suma importância quando o assunto é a pessoa idosa, pois têm como objetivo contribuir para a melhoria no estilo de vida e ajudar no processo de envelhecimento saudável. Objetivos: Relatar a experiência vivenciada pela acadêmica do curso de enfermagem da Universidade Federal do Amazonas - UFAM, em um programa de extensão universitária cujo público-alvo são idosos. Metodologia: Na perspectiva dos cuidados, buscou-se organizar ações de modo que todos interagissem, desenvolvendo atividades nas quais os idosos pudessem atuar como protagonistas das suas histórias, através de atividades físicas, cognitivas e psicossociais. Como estratégia, foram realizadas oficinas de dança, oficinas de relaxamento, oficinas com bolinhas, oficinas de memória, oficinas artísticas, rodas de conversa com temas diversos e participação nas datas festivas, como a festa junina que possibilitou a interação social dos idosos. Além das práticas de aferição da pressão arterial, aferição da glicemia, visita domiciliar e educação em saúde de forma individual, que ocorriam conforme a necessidade de cada idoso, abordaram-se temas como, por exemplo, autocuidado, hipertensão, diabetes e doenças cardiovasculares. Cabe salientar que as atividades ocorreram por um período de seis meses e de forma variada, exceto a aferição da pressão arterial, que era realizada em todos os encontros. Resultados: As atividades desenvolvidas contribuem de forma significativa para a melhoria da qualidade de vida dos idosos, visto que se proporciona momentos de lazer, interação social, cuidado com a saúde e atividades educativas que geram um processo de ensino e aprendizado com as trocas de experiências e fortalecimento do cuidado. Cabe salientar que através da visita domiciliar, onde são realizadas as consultas de enfermagem, se faz o acompanhamento da pressão arterial, dos níveis glicêmicos e das necessidades de cada idoso. Conclusões e Contribuições para a Enfermagem: A experiência vivenciada proporcionou senso crítico e criativo para elaborar estratégias que visam contribuir para a melhoria do estilo de vida da pessoa idosa. Trabalhar o envelhecimento saudável é bastante gratificante e requer habilidade científica, técnica e humana, sendo indispensável conhecer o mundo que os cercam para alcançar os resultados benéficos. Ao final do semestre, com a avaliação das atividades por parte dos idosos, foi possível enxergar o quanto o profissional de enfermagem contribui, de forma significativa, para a qualidade de vida da pessoa idosa. 


\section{Referências:}
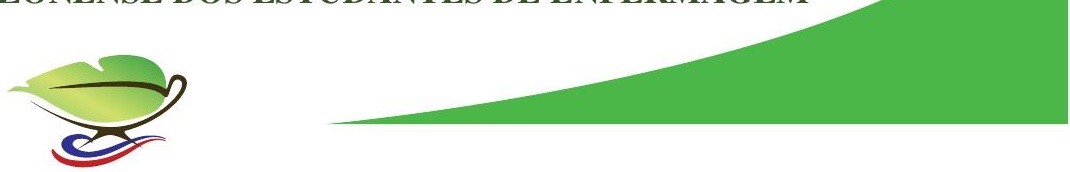

1. ONU. Mundo terá 2 bilhões de idosos em 2050 [Internet]. Brasília: Nações Unidas no Brasil. Atualizado em 2014. [acesso em: 09 de outubro de 2018]. Disponível em: https://nacoesunidas.org/mundo-tera-2-bilhoes-de-idosos-em-2050-oms-diz-queenvelhecer-bem-deve-ser-prioridade-global/.

2. IBGE. Projeção da população [Internet]. Brasília. Atualizado em 2016. [acesso em: 09 de outubro de 2018]. Disponível em: http://www.ibge.gov.br/home/estatistica/populacao/projecao_da_populacao/2008/pira mide/piramide.shtm.

3. Pereira EF, TEIXEIRA CS, SANTOS A. Qualidade de vida: abordagens, conceitos e avaliação. 2012 [acesso em 2018 out 08]; 26 (2): 241-250. Disponível em: http://www.scielo.br/scielo.php?pid=S1807-55092012000200007\&script=sci_arttext.

Descritores: Cuidados de Enfermagem; Idoso; Qualidade de Vida; 


\title{
O SETEMBRO AMARELO E A CAMINHADA PELA VIDA: RELATO DE EXPERIÊNCIA
}

\author{
Raquel de Oliveira Lopes \\ Graziela daSilvaMoura \\ E-mail do autor correspondente:mouragraziela691@gmail.com
}

Introdução: O setembro amarelo é o mês mundial de prevenção do suicídio. No Brasil, desde 2015, foi criada a campanha Setembro Amarelo, uma inciativa do Centro de Valorização da Vida (CVV), Conselho Federal de Medicina (CFM) e da Associação Brasileira de Psiquiatria (ABP), com o intuito de desenvolver eventos que criem espaço para debates sobre suicídio e divulgar o tema, alertando a população sobre a importância de sua discussão ${ }^{(1)}$. Um dos alertas é a alta taxa de suicídio entre idosos com mais de 70 anos. Envelhecer é um processo inerente ao ciclo vital, com mudanças que podem se concentrar ou disseminar-se nos aspectos físicos, financeiros, psicológicos, emocionais e estruturais ${ }^{(2)}$. Nesse contexto, a educação em saúde surge como uma estratégia para explanação a respeito do tema, pois é uma ferramenta de construção de conhecimento com o objetivo de promover a saúde do idoso e fazer com que o envelhecimento seja saudável e ativo, como preconizado nas políticas públicas de saúde ${ }^{(3)}$.Objetivo Geral: Relatar a experiência de discentes do curso técnico de enfermagem em práticas de educação em saúde abordando o tema "Suicídio: falar é a melhor opção", realizada através de uma caminhada com um grupo da terceira idade em uma associação de idosos local, em alusão ao setembro Amarelo. Objetivos Específicos: Orientar e sensibilizar os participantes quanto à temática, explicando sobre os principais sinais de vulnerabilidade ao suicídio e como auxiliar frente à situação. Metodologia: $\mathrm{O}$ presente trabalho refere-se a uma ação realizada no mês de setembro de 2018, em uma associação de idosos local, executada por alunos do curso técnico de enfermagem de uma instituição de ensino privado de Manaus, sob a supervisão da preceptora e com a participação de diversos profissionais que trabalham com a terceira idade em alusão ao setembro Amarelo, mês de prevenção ao suicídio. A execução da ação correu em dois momentos: no primeiro, os discentes participaram de uma gincana junto com os idosos, implementando ações de saúde como aferição da pressão arterial, coleta de glicemia, oferta de lanches e premiações para os vencedores da gincana; o segundo momento culminou com a realização da caminhada pelas principais praças do centro da cidade. Para orientar sobre a temática, os alunos elaboraram uma breve explicação sobre o setembro Amarelo e a prevenção ao suicídio. Durante a ação, os alunos se caracterizaram, fizeram faixas e promoveram distribuição de panfletos sobre o tema. Resultados: Mesmo com limitações e particularidades, a caminhada contou com aproximadamente 1500 idosos, de ambos os sexos e com uma faixa etária acima de 60 anos. A ideia norteadora dessa (ação, intervenção???) culminou no enriquecimento do diálogo entre os profissionais de saúde e terceira idade através de discussões, reflexões e práticas sobre a importância de se falar sobre o suicídio, e que os mesmos possam expressar suas angústias e acontecimentos vividos, a fim de contribuir com a expressão dos sentimentos das mesmas, sem julgamento. Conclusão e contribuições para enfermagem: $\mathrm{Na}$ realização dessa prática, os alunos do curso técnico de enfermagem perceberam que o pouco que se faz para a melhoria do estilo de vida da pessoa idosa é gratificante, pois percebeu-se que 
quando a equipe de enfermagem realiza suas atividades junto à terceira idade, através de uma forma de cuidar que trata o idoso em sua forma integral, considerando tanto suas necessidades físicas e biológicas como os aspectos biopsicossociais e espirituais, demonstra que essa concepção de cuidar prevê a interação das multidimensões do viver da pessoa idosa, para promover um vida saudável e ativa por meio da utilização das capacidades e condições de saúde do idoso, visando ao seu contínuo desenvolvimento pessoal, de forma a estimular sua autonomia. Dessa forma, praticar educação em saúde com a terceira idade é uma estratégia que enriquece a formação acadêmica e profissional dos discentes e fortalece a óptica da Educação em Saúde como ferramenta eficaz de intervenção e promoção a saúde.

\section{Referências:}

1. Centro de Valorização da Vida- CVV [homepage da internet]. Setembro Amarelo. Brasil, 2018. [ Acesso 01 de outubro de 2018]. Disponível em:> http://www.setembroamarelo.org.br/.

2. Dos Santos, A. S., de Assis Gomes, B. K., \& de Mesquita, K. S. F. [homepage da internet] Ação educativa em saúde sobre prevenção de suicídio com um grupo de idosas: relato de experiência [acesso 01 de outubro de 2018 ]. Disponível em:www.editorarealize.com.br/...TRABALHO_EV075_MD4_SA4_ID2577_221020170

3. Lima; J M F; Jaime, G F; Cavalcante, S.M.; Mendonça, A. N; Nobre, S. C.N. [homepage da internet]. "Setembro amarelo": Relato de experiência de acadêmicas do curso de Terapia Ocupacional em uma vivência em educação em saúde na prevenção ao suicídio. Anais do V Congresso de Educação em Saúde da Amazônia; 08 a 11 de novembro de 2016; Belém. Universidade Federal do Para:2016. [Acesso em 30 setembro de 2018]; [aproximadamente $3 \quad$ p]. Disponível em:http://www.coesa.ufpa.br/arquivos/2016/expandidos/relato_de_experiencia/educacao _em_saude/rel291.pdf.

Descritores: Educação em Saúde, Saúde da População Idosa; Suicídio; 


\title{
A EDUCAÇÃO EM SAÚdE COMO FERRAMENTA PARA FALAR DE MENINGITE: UM RELATO DE EXPERIÊNCIA
}

\author{
Mylena Silva de Souza \\ Luan Augusto Penha de Souza \\ Nair Chase da Silva \\ E-mail do autor correspondente: mylena.98ss@gmail.com
}

Introdução: A atuação da enfermagem encontra-se, principalmente, nos eixos de educação, assistência e pesquisa. Uma Instituição de Ensino Superior do município de Manaus desenvolveu, com os discentes de Enfermagem, ações de Educação em Saúde que, segundo Falkenberg et al. ${ }^{1}$, "é prática privilegiada no campo das ciências da saúde, em especial da saúde coletiva, uma vez que pode ser considerada no âmbito de práticas onde se realizam ações em diferentes organizações e instituições por diversos agentes dentro e fora do espaço convencionalmente reconhecido como setor saúde", propiciando o conhecimento acerca do impacto que as intervenções educativas em Saúde têm para a população. Vale ressaltar que houve aplicação de Metodologia Ativa na prática educativa que, segundo Mitre et al. ${ }^{2}$, a utilização de metodologias ativas no processo de educação facilita a transmissão e fixação de ideias por parte do público-alvo da mensagem, pois percebe-se como protagonista no processo de aprendizagem, dialogando e fazendo uma reflexão crítica acerca do tema, garantindo êxito na aquisição de conhecimento. Objetivo: Relatar as vivências durante a primeira prática educativa em saúde realizada pelos acadêmicos de enfermagem. Metodologia: A Ação Educativa em Saúde foi desenvolvida sobre o tema Meningite, tendo como público-alvo funcionários de uma empresa terceirizada que presta serviço na IES. Os discentes envolvidos na ação estavam responsáveis por compartilhar o conhecimento acerca do tema, sob a supervisão da professora da disciplina. A ação ocorreu na própria Instituição de Ensino, no dia 03 de maio de 2018. Iniciou através de roda de conversa, onde os discentes participantes buscaram entender os conhecimentos prévios dos funcionários acerca da Meningite. Após as respostas do público-alvo, os acadêmicos fizeram exposição sobre: o que é a meningite; tipos; formas de contágios; sinais e sintomas; e a importância da vacina estabelecida para meningite bacteriana. Desse modo, a dinâmica de verdadeiro ou falso foi utilizada como avaliação, onde os alunos arguiam os participantes, buscando informações e conceitos acerca do tema abordado e o público-alvo diria se era $\mathrm{V}$ ou $\mathrm{F}$. Foi um momento de muita descontração e aprendizagem. Resultados: Percebeu-se a pouca informação dos funcionários a respeito do tema. Assim, realizamos um desenho mostrando as meninges, o que esclareceu o conteúdo, e sobre a vacina contra a Meningite bacteriana, uma vez que esse método de prevenção é o mais eficaz no combate a esta doença, mas os participantes não conheciam. Então, realizamos esclarecimento das dúvidas, além de apresentar o tema de forma sucinta e clara. Desse modo, foram levantados dados das evidências acerca da Meningite e a sua taxa de letalidade atual no Brasil. Com todas as informações expostas na ação, notou-se a reflexão do público-alvo, onde os mesmos relataram que terão um olhar mais empático para as vacinas e buscarão estratégias para ampliar os conhecimentos acerca da Meningite aos seus familiares. Conclusões e contribuições ou implicações para a Enfermagem: As ações educativas em saúde possuem um impacto direto na vida do paciente ou individuo, e o enfermeiro necessita empoderar-se de seus conhecimentos científicos com o intuito de disseminar as 
informações necessárias para reversão ou prevenção de determinado quadro. Percebemos, através do contato frente à prevenção, resultante da disseminação de informações, que a enfermagem é importante aliado no cuidado com a saúde da população. Percebeu-se, também, que as práticas de Educação em Saúde necessitam estar presentes em todos os níveis de atenção, e cabe à Enfermagem socializar as informações através do educar, visto que enfermagem empoderada é enfermagem educadora. Por fim, percebeu-se que a educação resulta em atitudes preventivas para que a população possa atingir qualidade de vida.

\section{Referências:}

1.Falkenberg MB, Mendes TPL, Moraes EP, Souza ME. Educação em saúde e educação na saúde: conceitos e implicações para a saúde coletiva. Ciênc. Saúde coletiva [Internet]. 2014 Mar [citado em: 2018 Out 14] v.19(n.3): pp 847-852. Disponível em: http://dx.doi.org/10.1590/1413-81232014193.01572013.

2.Mitre SM; Batista RS; Mendonça JMG; Pinto NMM; Meirelles CAB; Porto CP et al. Metodologias ativas de ensino-aprendizagem na formação profissional em saúde: debates atuais. Ciênc. saúde coletiva. 2008; [citado em 28 de setembro de 2018]; v.13 (Supl. 2) pp 2133-2144. Disponível em: http://dx.doi.org/10.1590/S1413-81232008000900018.

Descritores: Educação em Saúde; Enfermagem; Meningite. 


\title{
A IMPORTÂNCIA DA MONITORIA ACADÊMICA COMO ESPAÇO NA ÁREA DA DOCÊNCIA: RELATO DE EXPERIÊNCIA
}

\author{
Handerson da Silva Pereira \\ Bruno dos Santos Araújo \\ Elizandra Freitas do Nascimento \\ Márcia Regina Praia Marins da Silva \\ Fabiane Veloso Soares
}

E-mail do autor correspondente: handersonsilva13@ hotmail.com

Introdução: A prática da monitoria é uma oportunidade para o estudante desenvolver habilidades próprias à docência, aprofundar conhecimentos na área específica e contribuir com o processo de ensino-aprendizagem dos alunos monitorados ${ }^{(1)}$. O monitor presta assistência ao professor e contribui com o aprendizado dos alunos, principalmente por ter contato direto e por esclarecer o assunto da disciplina. Durante a vivência da monitoria, o estudante descobre se tem vocação para atuar na docência ${ }^{(2)}$. O aluno monitor tem ganhos significativos principalmente porque consegue ampliar e aprimorar seus conhecimentos em uma determinada disciplina, obtendo a prática que irá favorecer sua atuação na docência ${ }^{(2,3,4)}$. Para ajudar no desempenho da disciplina de anatomia, utilizaram-se peças sintéticas, atlas, cadáver e aulas práticas. A monitoria funciona como um preparatório para os acadêmicos que querem ingressar na área da docência. Objetivo: Descrever a vivência como monitores acadêmicos no curso de enfermagem, assim como a importância da monitoria como instrumento de aprendizagem e desenvolvimento discente. Metodologia: Trata-se de um relato de experiência, realizado no período de março a novembro de 2017, quando acadêmicos de enfermagem atuaram como monitores em disciplinas do curso de graduação em enfermagem. Utilizou-se o método de diálogo e observação, no qual o monitor participa e mantém um elevado grau de contato e envolvimento com os outros alunos, compartilhando seus conhecimentos e algumas informações a respeito da disciplina, fazendo com que aconteça ensino-aprendizagem, assim obtendo uma melhor experiência voltada para sua atuação na docência. Resultados: Através da monitoria acadêmica no curso de enfermagem vivenciamos, além das atividades inerentes ao monitor, o exercício da prática docente, o que favoreceu a identificação com a área da docência. Ainda foi possível manter um relacionamento interpessoal com os discentes responsáveis pelas disciplinas. Acreditamos que a monitoria é um passo para os estudantes que desejam se tornar professores, pois o tempo como monitor faz com que seu conhecimento fique cada vez mais amplo e aumente sua dedicação para aprender cada vez mais para poder repassar o conhecimento obtido. Conclusões e implicações para a Enfermagem: Nessa perspectiva, a monitoria acadêmica colabora com o desenvolvimento da aprendizagem e liderança dos monitores. Mostra ao aluno de enfermagem que, além de atuar na assistência, o enfermeiro também pode atuar como docente. 


\section{Referências:}

1. Assis FD, et al. Programa de monitoria acadêmica: percepções de monitores e orientadores. Rev. Enferm. Uerj, 2006; jul-set; 14(3): 391-397.

2. Schneider MSPS. Monitoria: instrumento para trabalhar com a diversidade de conhecimento em sala de aula. Revista eletrônica espaço acadêmico, 2006; Mensal (65).

3. MATOSO, L. M. L. A importância da monitoria na formação acadêmica do monitor: um relato de experiência. Catussaba, Mossoró, v.3, n.2, p.77-83, 2014. Disponível em: $\quad$ https://repositorio.unp.br/index.php/catussaba/article/view/567/461>. Acesso em 01 out. 2017.

4. Influência da Monitoria Acadêmica no Processo de Ensino e Aprendizagem em Psicologia, Clínica \& Cultura v.2, n.1, jul-dez, 2016, 36-43. Assis, F., Borsatto, A. Z., Silva, P. D. D., Peres, P. L., Rocha, P. R., \& Lopes, G. T. (2006). Programa de monitoria acadêmica: percepções de monitores e orientadores. Revista de Enfermagem da UERJ, 14 (3), 391-397.

Descritores: Monitoria; Docência; Ensino-Aprendizagem. 


\title{
DESENVOLVIMENTO DE UM SOFTWARE GUIADO PELO PROCESSO DE ENFERMAGEM PARA AUXILIAR O ENFERMEIRO NA AVALIAÇÃO E TRATAMENTO DE LESÃO POR PRESSÃO
}

\author{
$\underline{\text { Júlio Cesar Oliveira de Souza }}$ \\ Leonam Bernardo Soares Matos \\ Nariani Souza Galvão \\ Sáskia Sampaio Cipriano de Menezes. \\ E-mail do autor correspondente: julio.volpy@icloud.com
}

Introdução: A prevalência de LP tem aumentado nos últimos anos devido à maior expectativa de vida da população, decorrente de avanços na assistência à saúde (1). No Brasil, a LP atinge aproximadamente $9 \%$ de todos os pacientes hospitalizados (2). Essas lesões são consideradas eventos adversos ocorridos durante a hospitalização e refletem, de forma indireta, a qualidade do cuidado prestado. Além disso, são uma complicação frequente em pacientes graves e têm grande impacto sobre sua recuperação e qualidade de vida (3). O uso da tecnologia na prática dos profissionais de saúde vem sendo empregado como uma ferramenta auxiliadora no processo de cuidar, visto que dinamiza a assistência, tornando, por vezes, o cuidar mais eficaz (4).Objetivo: Desenvolver um software guiado pelo processo de enfermagem para auxiliar o enfermeiro na avaliação e tratamento de Lesão por Pressão, a partir do processo de enfermagem. Metodologia: Trata-se de um aplicativo com pesquisa metodológica descritiva e exploratória, cujo método de coleta de dados ocorrerá através de abordagens quantitativas. Foi dividido em seis etapas: levantamento do estado da arte atual, definição das funcionalidades principais do software e como os processos atuais podem ser melhorados com a utilização do aplicativo; Projeto da Arquitetura e Setup dos ambientes de desenvolvimento; implementação do Algoritmo principal de coleta; desenvolvimento das Telas/Cenários, definição e criação da interface gráfica; tratamento dos dados adquiridos, nessa etapa será desenvolvido a parte de integração com as IDE'S para Mobile/PC; depuração e testes no aplicativo. O sistema a ser desenvolvido contará com a orientação e ajuda de profissionais da área de computação. O software é destinado a plataformas tecnológicas portáteis e móveis. Resultados alcançados: Até o mês de setembro já foi iniciada a construção da revisão de literatura, e desenvolvidas as telas de início, login, consulta de melhores evidências (WebView), análise de requisitos do banco de dados, criação e instalação do mesmo e tela do componente destinado a anamnese e avaliação específica da lesão. Seguimos trabalhando no desenvolvimento de cada ferramenta do aplicativo. Conclusões e contribuições ou implicações para a Enfermagem: $O$ uso de um software que auxilie o enfermeiro através do processo de enfermagem na avaliação e tratamento de pacientes com LP, trará novas ferramentas do cuidado, além de contribuir cientificamente para o enriquecimento da literatura nacional e crescimento do profissional enfermeiro da região amazônica, uma vez que esse tipo de estudo é inédito na região norte. 


\section{Referências:}

1. MOORE, Z; ; et al. Pressure ulcer prevalence and prevention practices: a crosssectional comparative survey in Norway and Ireland. Journal of Wound Care.v.24, n.8, 2015.

2. FREITAS, M.C.; MEDEIROS, A.B.F.; GUEDES, M.V.C.; ALMEIDA, P.C; GALIZA, F.T; NOGUEIRA, J.M. Úlcera por pressão em idosos institucionalizados: análise da prevalência e fatores de risco. Rev. Gaúcha Enferm. v.32, n.1, p.143-50, 2011. 3. Silva K L, Évora YDM, Cintra CSJ. Desenvolvimento de software para apoiar a tomada de decisão na seleção de diagnósticos e intervenções de enfermagem para crianças e adolescentes. Rev. LatinoAm. Enfermagem. [Ínternet] 2015.

4. Danski, M. T. R., Liedke, D. C. F., Vayego, S. A., Pontes, L., Lind, J., \& Johann, D. A. (2016). Tecnologia Bota De Unna Na Cicatrização Da Úlcera Varicosa. Cogitare Enfermagem, 21(3), 1-9.

Descritores: Lesão por pressão; Segurança do paciente; Software. 


\title{
PERCEPÇÃO DOS IDOSOS EM RELAÇÃO AO CONVÍVIO EM INSTITUIÇÕES DE LONGA PERMANÊNCIA
}

\author{
Dhayanna Lima \\ Eurides Souza \\ E-mail do autor correspondente:dhayanna10lima@gmail.com
}

Introdução: Com o passar dos séculos, a humanidade vem alcançando a longevidade. Isso demonstra ser o resultado do avanço da medicina e surgimento de novas tecnologias 1 . O envelhecimento tem características biológicas e psicológicas que afetam o indivíduo. Mencionando algumas características, podemos dizer que o envelhecimento biológico ou fisiológico é implacável, ativo e irreversível, causando debilidade no organismo, diminuição de hormônios, modificações internas e externas de natureza multifatorial. Já o envelhecimento psíquico ou amadurecimento não é naturalmente progressivo nem implacável e que não acontece com a passagem do tempo necessariamente, mas ocorre mediante esforço pessoal contínuo em buscar autoconhecimento e o sentido da vida2. A região norte apresenta uma menor porcentagem de idosos comparando com as demais regiões. Isso foi confirmado por meio do censo do IBGE 2010 que explicou a baixa porcentagem de idosos, que se deve aos altos níveis de fecundidade do passado, o que resulta em um alto índice de jovens e adultos na população. Outro fator importante é a perda da atratividade agrícola dessa região nos últimos anos. Desse modo, o envelhecimento também se manifesta segundo as variações e desequilíbrios regionais, principalmente sociais e econômicos 3 . Nesse contexto, temos as instituições de longa permanência que antes eram conhecidas como asilos. Definem-se como estabelecimentos que prestam assistência integral institucional, cujo público-alvo são as pessoas de 60 anos ou mais, dependentes ou independentes, que não dispõem de condições para permanecer com a família ou em seu próprio domicílio4. Objetivo: Analisar a percepção dos idosos em relação ao convívio na instituição de longa permanência. Metodologia: Estudo descritivo, baseado na abordagem qualitativa e observação direta e extensiva por meio da aplicação de um questionário. Participantes do estudo: 20 idosos residentes na instituição; Critérios de inclusão: ambos os sexos, em condições de se comunicar verbalmente, compondo uma amostra de 20 idosos. De acordo com as recomendações éticas e legais contidas na Resolução 466/12 do Conselho Nacional de Saúde (CNS), que trata das pesquisas envolvendo seres humanos (BRASIL, 2012). Submetido à Plataforma Brasil e ao NEPEM (núcleo de estudo e pesquisa sobre o envelhecimento em Manaus). Somente após a aprovação, a coleta de dados será realizada Resultados esperados: Espera-se com a pesquisa a melhoria da qualidade de vida da pessoa idosa enquanto institucionalizada. Conclusões e contribuições ou implicações para a Enfermagem: Portanto, a pesquisa contribuirá para ampliação teórica a respeito do cuidado prestado pela enfermagem nas instituições de longa permanência, considerando que a mesma tem um papel fundamental na assistência e colaborará seguramente para a melhoria na qualidade de vida dos idosos institucionalizados. 


\section{Referências:}

1. SILVA, Maria do Rosário de Fátima e. Envelhecimento e proteção social: aproximações entre Brasil, América Latina e Portugal. 1. ed. São Paulo: Serv. Soc. Soc., 2016. 215 p.

2. MORAES, Edgar Nunes de; MORAES, Flávia Lanna de; LIMA, Simone de Paula Pessoa. Características biológicas e psicológicas do envelhecimento. 1. ed. Belo Horizonte: RevMed Minas Gerais, 2010. 68 p.

3. MAFRA, Simone C. T. et al. O envelhecimento nas diferentes regiões do Brasil: uma discussão a partir do censo demográfico 2010. 1. ed. Capinas Grande: Realize, 2013.

4. COSTA, Maria Carla N. S.; MERCADANTE, Elizabeth Frohlich. O Idoso residente em ILPI (Instituição de Longa Permanência do Idoso) e o que isso representa para o sujeito idoso. 16. ed. São Paulo: Revista Kairós Gerontologia, 2013. 213 p.

Descritores: Percepção; Idosos; Instituição de longa permanência. 


\title{
PERCEPÇÃO DE ACADÊMICOS DE ENFERMAGEM FRENTE À VIVÊNCIA DE PRÁTICAS EDUCATIVAS COM CRIANÇAS NA CRECHE
}

\author{
Ana Gabriela Lucena Brito \\ Maisa Silva de Castro \\ Natália Rayanne Souza Castro \\ Samuel Lima Ferreira \\ Felipe Alves de Almeida \\ Arinete Veras Fontes Esteves \\ E-mail do autor correspondente: gabriela.lucenab@hotmail.com
}

Introdução: A creche é um local propício para o crescimento e desenvolvimento da criança, visto que integra aspectos físicos, psicológicos, intelectuais e sociais, juntamente com a família e comunidade ${ }^{1}$. É um espaço que possibilita a construção biopsicossocial, pois trabalha com questões básicas da infância, como a socialização, educação e o intelecto. Por ser a fase mais delicada da vida do indivíduo, deve ser trabalhada com atenção, utilizando as melhores ferramentas disponíveis para a formação da criança ${ }^{2}$. Objetivo: Explanar acerca da vivência de acadêmicos em graduação de Enfermagem em práticas educativas para crianças em uma creche do município de Manaus, visando à promoção do autocuidado e da prevenção de comorbidades infantis. Metodologia: As realizações das atividades se deram através de um Programa Institucional de Bolsa de Extensão (PIBEX), o qual os acadêmicos de uma Instituição de Ensino Superior (IES) do município de Manaus, do curso em graduação de Enfermagem, integravam. As atividades se deram semanalmente abordando eixos da saúde: Higiene das Mãos, Saúde Bucal, Pediculose, Imunização. Os acadêmicos apresentaram os temas na forma de dramatização nos cenários de prática da saúde, interagindo com o público; utilizando cartazes com ilustrações e maquetes para melhor análise das crianças. O público-alvo foi estimulado a participar de jogos de quiz para avaliação do seu aprendizado, e de pinturas para fim lúdico. Resultados: As ações lúdicas e dramatizadas das temáticas envolvendo a promoção da saúde foram bem aceitas pelas crianças. Essas participaram de forma ativa, contribuindo com experiências próprias durante a execução das atividades. As metodologias ativas utilizadas foram importantes, pois levaram a melhor compreensão das etapas da higienização das mãos, processo de higiene bucal, mecanismo de transmissão da pediculose e mecanismo de ação das vacinas. Ao final das atividades, foi possível verificar que as crianças compreenderam as informações explanadas, pois quando questionadas sobre a importância do autocuidado e conhecimento do corpo foram capazes de expor o conhecimento compartilhado. Conclusões e contribuições ou implicações para a Enfermagem: No ambiente da creche, deve-se prestar cuidados em saúde no que diz respeito à higiene pessoal, à alimentação, atividades recreativas, promoção da interação e o contato com os demais envolvidos. A educação em saúde no âmbito da creche é de suma importância na contribuição da formação profissional do enfermeiro e no auxílio ao autocuidado das crianças, visto que é uma das atividades competentes ao profissional de enfermagem, garantindo assim uma assistência de 
enfermagem integral, qualificada, científica e voltada para a promoção e prevenção da saúde nesta fase infantil.

\section{Referências:}

1. Araújo MG, Cassiano AN, Holanda CSM, Moreira PVSQ, Giovannini PE. Health education in the childhood education: active methodologies in approaching of the extensionist action. J Nurs UFPE on line [Internet]. 2013 Jan [cited 2017 May 21];7(1):306-13. Disponívelem: http://www.revista.ufpe.br/revistaenfermage m/index.php/revista/article/view/3470/pdf_1936

2. Faria ML, Wichr P. Creche, criança e saúde. Rev Min Enferm online [internet]. 2014 janeiro-março. $\quad 18(1)$ : $142-146$

Disponível

em:

http://pesquisa.bvs.br/brasil/resource/pt/bde-25585

Descritores: Creche; Educação em saúde; Saúde da criança. 


\title{
RELATO DE EXPERIÊNCIA: EDUCAÇÃO EM SAÚDE SOBRE PRÁTICAS RESPIRATÓRIAS NA ÓTICA DE ACADÊMICOS DE ENFERMAGEM
}

\author{
$\underline{\text { Robson de Oliveira Felix }}$ \\ Railton da Silva Miranda \\ Alice Lima Macedo \\ George Lucas Augusto Trindade da Silva \\ Stheffany da Silva Pinheiro \\ E-mail do autor correspondente: robfelix.oliveira@gmail.com
}

INTRODUÇÃO: As práticas educativas em saúde são importantes instrumentos para a promoção e prevenção. A escolha de métodos que estimulem os sujeitos a melhorarem sua qualidade de vida, é um ponto fundamental para o êxito no eixo profissional ${ }^{1}$. As ações em saúde não são necessariamente por métodos sofisticados, pois alcançam bons resultados com metodologias simples e ativas, tendo assim a acessibilidade como foco. Esses conhecimentos, por sua vez, servem como princípio norteador da qualidade de vida dos indivíduos ${ }^{2}$. OBJETIVO: Relatar a experiência vivenciada por acadêmicos de enfermagem sobre as ações de práticas corporais respiratórias na educação em saúde, durante a disciplina de administração hospitalar, no período de 2018/1. METODOLOGIA: Trata-se de um estudo qualitativo, de caráter descritivo, do tipo relato de experiência, vivenciado por acadêmicos de enfermagem em uma instituição de ensino fundamental e médio privada, localizada no bairro de Flores, Manaus- AM. A escola possui um número médio de 100 alunos matriculados no ensino fundamental 1 nos períodos matutino e vespertino. Houve perspectiva da educação em saúde, em consonância com as práticas corporais com crianças para promover saúde respiratória. Para a promoção em saúde respiratória, utilizou-se da premissa de materiais simples e de fácil acesso para que se pudesse realizar atividades de complacência pulmonar, extensão e boa função dos pulmões. Os materiais utilizados foram; barbante e copos descartáveis. Foi estimulada a prática de exercício respiratório em sala e, logo após as atividades, foi trabalhada, junto aos alunos, a educação em saúde sobre a importância dessa prática e seus benefícios. A professora responsável pela turma também foi orientada a realizar a atividade com os alunos, visto que é algo simples, com baixo custo e que também promove grande interatividade na sala de aula. RESULTADOS: A atividade de promoção da saúde ocorreu da seguinte forma: os alunos, de uma maneira totalmente interativa, seriam avaliados quanto à complacência pulmonar e extensão da capacidade funcional dos pulmões. Já existem atividades que propõem a avaliação pulmonar, entretanto, a sua observação por meio de atividades lúdicas em educação em saúde é de certa forma pouco explorada ${ }^{3}$. Os materiais utilizados foram de baixo custo (barbantes e copos descartáveis), a atividade consistia em os alunos, "assoprando o ar" de forma rítmica, passarem o copo de um lado do barbante até a outra extremidade. As crianças conseguiram obter um bom desempenho na atividade proposta. Percebeu-se que nesta idade é muito importante a promoção em saúde; todos os alunos mantiveram uma boa complacência e boa capacidade funcional dos pulmões. Durante a atividade, nenhum aluno precisou de pausa por cansaço. CONCLUSÕES E CONTRIBUIÇÕES OU IMPLICAÇÕES PARA A ENFERMAGEM: Portanto, quando se associa o 
conhecimento em saúde e a sua prática para promover as práticas respiratórias e não apenas intervir no paciente doente, percebe-se como a atuação do enfermeiro na atividade de promoção é eficaz. Dessa forma, expande-se não só a atuação do profissional e dos acadêmicos de enfermagem nessa prática, como também impacta na qualidade de vida da sociedade como um todo. As crianças participantes da atividade tiveram a possibilidade de se distanciar dos agravos e doenças através da promoção em saúde.

\section{Referências:}

1. Monteiro EMLM, Vieira NFC. Health education based on culture circles. Rev. bras. enferm. 2010;63(3):397-403.

2. Lucchese R, Nascimento FK, Vera I, Felipe RL, Fernandes IL, Bueno AA. Educação em saúde com pessoas usuárias de álcool e outras drogas.CogitareEnferm. 2016 Out/dez; 21(4): 01-10.

3. Dias VP, Silveira DT, Witt RR. Educação em saúde: o trabalho de grupos em atenção primária. Rev APS [Internet]. 2009 [acesso em 2018 set 16];12(2):221-7. http://www.aps.ufjf.br/index.php/aps/articl e/view/330/205.

Descritores: Enfermagem; Educação em saúde; Exercícios respiratórios. 


\title{
RELATO DE EXPERIÊNCIA: IMPRESSÕES SOBRE A INSERÇÃO DA REALIDADE VIRTUAL EM SAÚDE NA DISCIPLINA PRÁTICAS INTEGRADAS EM UM CURSO DE ENFERMAGEM NO AMAZONAS.
}

\author{
Alice Lima Macedo \\ Railton da Silva Mirando \\ Robson de Oliveira Felix \\ Stheffany da Silva Pinheiro \\ E-mail do autor correspondente:alicemaceda7@gmail.com
}

INTRODUÇÃO: A realidade virtual em saúde teve sua criação e desenvolvimento na década de 30. Porém, sem investimentos na área, tornou-se por anos obsoleta, sendo usada apenas nas forças armadas. A realidade virtual em saúde teve sua expansão em universidades e institutos educacionais e hospitalares depois de décadas de funcionamento (1). Portanto, um dos focos de preferência para desenvolvimento de atividades são as áreas de ciências da saúde - medicina; essa forte expansão possibilitou assim novos horizontes para o estudo de disciplinas como Anatomia, Patologia Geral Técnica Cirúrgica, Semiologia e Práticas Integradas. O aluno consegue, em uma realidade tridimensional, trabalhar de uma forma mais atuante na aprendizagem (2). OBJETIVO: Relatar a experiência de inserção da realidade virtual em saúde na disciplina práticas integradas. METODOLOGIA: Trata-se de um estudo descritivo e exploratório do tipo relato de experiência. Os sujeitos da experiência são acadêmicos de enfermagem de uma universidade privada localizada no bairro de Flores, Manaus, AM. Os alunos da disciplina práticas integradas VIII encontram-se no $8^{\circ}$ período; os mesmos fizeram uso do "OculusRift", o mais moderno em termos de realidade virtual. RESULTADOS: Nas aulas de propedêutica renal e cardiorrespiratória, utilizou-se a metodologia ativa de ensino. Os alunos, no início da aula, responderam ao questionário interativo, sendo essa parte para observação do conhecimento prévio dos acadêmicos. Em sequência, em vez de os alunos utilizarem a aula expositiva e dialogada, foram submersos no mundo da realidade virtual, onde eles tiveram a oportunidade de vivenciar as estruturas anatômicas em 3 dimensões, utilizaram, na realidade virtual, o processo de filtração e reabsorção renal; na área cardiorrespiratória, os acadêmicos estiveram em frente ao coração tridimensional, com os sons característicos e o traçado do eletrocardiograma. Dessa forma, houve uma facilidade maior de trabalhar, em partes, cada uma das funções, de forma que os alunos tivessem um maior aproveitamento e, a aula que antes era planejada em 3 momentos, sendo 1 teórico, um de laboratório e outro prático, tornou-se uma aula aonde os 3 processos ocorrem ao mesmo tempo. Otimizou-se os métodos de ensino, bem como a aprendizagem dos alunos. CONCLUSÕES E CONTRIBUIÇÕES OU IMPLICAÇÕES PARA A ENFERMAGEM: A enfermagem, como outros cursos, encontra-se em franco desenvolvimento em sua metodologia. A realidade virtual em saúde é um campo ainda pouco descoberto no âmbito da educação superior em saúde no Brasil; a implementação desse projeto piloto no curso de enfermagem visa transformar as aulas expositivas e dialogadas em aulas de aprendizado de times baseado em problemas, um momento onde os eixos teóricos e práticos se relacionam, e tanto os acadêmicos quanto seus professores desenvolvem estratégias mais eficazes de ensino e aprendizagem. 


\section{Referências:}

1.Montero, E F de S, e col. Realidade virtual e a medicina. Informe Técnico. Acta Cirúrgica Brasileira - Vol 18 (5) 2003 - 489

2.Korkes F., Wroclawski ML., Tavares A. Castro-Neves Neto O, Tobias-Machado M, Pompeo ACL, Wro- clawski E: Video game as a preoperative warm-up for laparoscopic surgery. Einstein 2009; 7: 462-4.

Descritores: Atitudes e Prática em Saúde, Realidade Virtual, Enfermagem. 


\title{
OCORRÊNCIA DE PNEUMONIAS NOSOCOMIAIS ASSOCIADAS À VENTILAÇÃO MECÂNICA EM PACIENTES INTERNADOS EM UNIDADES DE TERAPIA INTENSIVA DE UM HOSPITAL ESPECIALIZADO EM DOENÇAS TROPICAIS DE MANAUS
}

\author{
David Brendo Souza Damião \\ Arimatéia Portela de Azevedo \\ E-mail do autor correspondente:davidbrendo1995@gmail.com
}

Introdução: As infecções hospitalares, também conhecidas como infecções relacionadas à assistência à saúde (IRAS), são grandes agravantes dos índices de morbimortalidade e, em centros de terapia intensiva (CTI), estão associadas, primariamente, à gravidade clínica dos pacientes, ao uso de procedimentos invasivos, como cateter venoso central, sonda vesical de demora e ventilação mecânica (VM), ao período de internação prolongado, à colonização por microrganismos resistentes e ao próprio ambiente do CTI, que favorece a seleção natural de microrganismos ${ }^{1}$. Segundo Amorim e Gomes (2015), a Pneumonia Associada à Ventilação Mecânica (PAVM) é a principal iatrogenia causada pelo uso dos Ventiladores Mecânicos. Esse termo é empregado quando a Pneumonia é diagnosticada em pacientes intubados que necessitam do uso da VM e, após 48 horas de utilização dessa tecnologia, apresentam os sintomas de infecção ${ }^{2}$. Cuidados de enfermagem: Para Moura e Silva (2016), as intervenções utilizadas para prevenção da PAVM são executadas pela equipe multiprofissional, em especial pela equipe de enfermagem, que é responsável pelo cuidado diário do paciente. Alguns cuidados de enfermagem podem se aplicar na identificação de pacientes colonizados e a utilização de precauções de contato, para evitar a disseminação de microrganismos através dos profissionais de enfermagem, elevação da cabeceira de $30^{\circ}$ e $45^{\circ}$, minimizando o risco de broncoaspiração e, consequentemente, da PAV, lavagem das mãos, higienização oral, controle de sinais vitais, aspiração de secreções pulmonares, mobilização do Tubo Orotraqueal (TOT), sincronismo entre paciente e máquina, controle nutricional, apoio emocional, controle de infecções, além da educação permanente para toda equipe multiprofissional, que presta cuidado a esses pacientes, para a conscientização do cuidado. Objetivos: Registrar a ocorrência de Pneumonias Associadas à Ventilação Mecânica em Unidades de Terapia Intensivas (UTI) de um hospital especializado em doenças tropicais de Manaus (FMT-DHV) e descrever o perfil epidemiológico dos indivíduos com PAVM nosocomial internados nas UTIs. Metodologia: Trata-se de uma pesquisa retrospectiva de caráter descritivo, com abordagem quantitativa, a fim de analisar a ocorrência de infecção hospitalar relacionada à ventilação mecânica - PAVM, desenvolvido por acadêmico da graduação em Enfermagem de uma Instituição de Ensino Superior de Manaus, com pacientes internados nas unidades de terapia intensiva da Fundação de Medicina Tropical Dr. Heitor Vieira Dourado (FMT/HVD), a qual analisou a ocorrência de infecções nosocomiais relacionadas à Ventilação Mecânica no período de janeiro a dezembro de 2017. As informações foram coletadas no banco de dados da UTI, setor vinculado à Comissão de Controle de Infecção Hospitalar (CCIH) da FMT/HVD. Resultados: Foram notificadas 53 infecções relacionadas à saúde nas duas UTI, sendo que $53 \%$ dos sítios de infecção acometidos foram do trato respiratório. O gênero mais afetado foi o masculino, com $75 \%$, e a faixa etária de maior prevalência foi a de pacientes 
com idades entre 32 a 47 anos. Conclusões e contribuições ou implicações para a Enfermagem: A implementação de estratégias de prevenção e esforços, que visem à melhoria da qualidade assistencial, é altamente relevante. É necessário, portanto, possibilitar ações de vigilância epidemiológica específicas e monitoramento de casos, a divulgação de dados aos profissionais envolvidos nos processos, o uso de instrumento de identificação de pacientes em risco, controle sobre os procedimentos assistenciais e intervenções imediatas são fundamentais no ambiente hospitalar, tendem a diminuir as taxas dessas infeções e, consequentemente, os óbitos a elas relacionadas.

\section{Referências:}

1. Silva, M C O; Moura R C M. Cuidados de enfermagem na prevenção da pneumonia associada à ventilação mecânica: revisão integrativa. Revista Cultural e Científica do UNIFACEX. v. 14, n. 2, 2016.

2. Amorim M M; Gomes, S R. Ações de enfermagem para prevenção de infecções associadas à ventilação mecânica na unidade de terapia intensiva neonatal. Revista Interdisciplinar do Pensamento Científico. ISSN: 2446-6778 № 2, Julho/Dezembro 2015.

Descritores: Ventilação mecânica, Infecção hospitalar, Pneumonia. 
ANAIS DO I CONGRESSO DOS ESTUDANTES DE GRADUAÇÃO E TÉCNICO DE ENFERMAGEM DO AMAZONAS/ IV ENCONTRO AMAZONENSE DOS ESTUDANTES DE ENFERMAGEM

\section{RESUMOS}

\section{EIXO 3: FORMAÇÃO DA EQUIPE DE ENFERMAGEM PARA O CUIDADO EM SAÚDE}

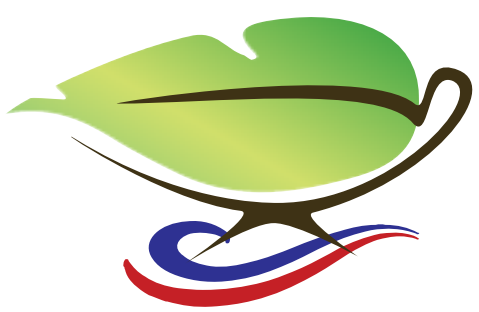




\title{
TUMOR DE WILMS: PERCEPÇÃO ACADÊMICA ACERCA DO CÂNCER PEDIÁTRICO
}

\author{
Thaís Karoline da Costa Macêdo Gralha \\ Jéssica Kelly Morais da Silva \\ E-mail do autor correspondente:karolinegralha@gmail.com
}

Introdução: O Tumor de Wilms, ou nefroblastoma, é a neoplasia renal maligna mais comum na infância. As causas estão relacionadas a fatores genéticos e ambientais, como substâncias químicas e agentes infecciosos. Os sintomas incluem a presença de massa abdominal palpável, febre, náuseas e perda de apetite. Tratando-se de um tumor unilateral, o procedimento realizado é a nefrectomia total e, em caso de tumor bilateral, a nefrectomia parcial é a indicada. ${ }^{1}$ Objetivos: Descrever a experiência vivenciada, enquanto acadêmica, durante a realização da visita domiciliar a uma paciente submetida a nefrectomia total por diagnóstico de Tumor de Wilms. Metodologia: Trata-se de um relato de experiência referente à visita domiciliar realizada a uma criança submetida à nefrectomia total à direita, por diagnóstico de Tumor de Wilms durante as práticas de campo da disciplina Enfermagem na Atenção Integral à Saúde da Criança e Adolescente, do curso de Enfermagem da Universidade Federal do Amazonas. Durante a visita domiciliar, ocorrida no dia 19 de outubro de 2017, realizou-se uma entrevista voltada à mãe para identificação e reconhecimento total da infante, seguida de exame físico geral e coleta de dados. Resultados: A visita domiciliar a uma criança submetida à nefrectomia total, por diagnóstico de nefroblastoma, proporcionou a vivência de uma situação de ensino- aprendizagem, pois ao cursar essa disciplina, a assistência de enfermagem voltada à criança ou ao adolescente com este tipo de carcinoma não fora mencionada e, com base na coleta de dados, só houve a possibilidade da realização do diagnóstico precoce por meio da observação da Agente Comunitária de Saúde (ACS) durante uma visita domiciliar, na qual a criança apresentava febre intermitente. A paciente estava nessa condição há três dias e a ACS comunicou o caso à enfermeira da Unidade Básica de Saúde da Família (UBSF), a qual se deslocou à residência da criança e, após realizar o exame físico, constatou a presença de uma massa abdominal palpável. A enfermeira e a médica da UBSF encaminharam a paciente ao Instituto de Saúde da Criança do Amazonas (ICAM), onde todos os procedimentos referentes ao tratamento do nefroblastoma foram realizados. Conclusões e contribuições para a Enfermagem: A ciência relativa ao protocolo de diagnóstico precoce do câncer pediátrico é pertinente na formação do enfermeiro, o qual atuará como generalista, intervindo nas mais diversas situações de saúde/doença, com base no rigor científico e pensamento crítico, como preveem as Diretrizes Nacionais Curriculares do curso de Enfermagem. ${ }^{2}$ 


\section{Referências:}

1. Ministério da Saúde (BR), Instituto Nacional de Câncer José Alencar Gomes da Silva. Consenso nacional de nutrição oncológica: paciente pediátrico oncológico. Rio de Janeiro (RJ); 2014.

2. Ministério da Saúde (BR), Secretaria de Atenção à Saúde. Departamento de Atenção Especializada e Temáticas. Protocolo de diagnóstico precoce do câncer pediátrico. Brasília (DF); 2017.

Descritores: Enfermagem; Tumor de Wilms; Visita Domiciliar. 


\title{
A VIVÊNCIA EM PROJETO EDUCATIVO: ENSINO SOBRE DOENÇAS TROPICAIS
}

\author{
Lorena Veiga Farias \\ Bruno Alexsander Matos Ferreira \\ Juliana Lima Lopes \\ Sandy Marques Libório de Queiroz \\ GilsireneScantelbury de Almeida \\ E-mail do autor correspondente: lore.veigafarias@gmail.com
}

INTRODUÇÃO: O Perfil do Enfermeiro requer um Profissional qualificado para o exercício da Enfermagem, com formação generalista, humanista, crítica, reflexiva e política, com base no rigor científico e intelectual, e pautado em princípios éticos/bioéticos ${ }^{1}$. A formação de profissionais de enfermagem exige um ensino de qualidade, que lhe confira domínio na realização de atividades assistenciais, gerenciais, de ensino e pesquisa. A partir dessa perspectiva, o Curso de Enfermagem, proporciona a inclusão de disciplinas com foco em Educação em Saúde, que estimula os alunos a realizarem ações que corroborem para a sociedade e para o desenvolvimento e construção do conhecimento acadêmico, possibilitando a atividade junto à comunidade, através da comunicação de temas relacionados à saúde ${ }^{2}$. OBJETIVO: Informar os alunos sobre a prevenção da doença de Chagas e febre amarela. METODOLOGIA: Trata-se de um relato de experiência, produto de uma atividade da disciplina Educação em Saúde, desenvolvida por 4 acadêmicos de Enfermagem de uma Universidade Federal. A atividade foi desenvolvida em uma instituição de ensino, na cidade de Manaus, direcionada aos alunos do ensino fundamental e médio. Utilizamos metodologias ativas que atendessem ao público, dentre elas, Teatro com fantoches; Tempestade de ideias e aula expositiva dialogada. Dividimos os tópicos relevantes da temática, os quais foram: Agentes etiológicos e vetores; ciclo de transmissão; medidas profiláticas e tratamento. Reunimos o material didático, empregamos a metodologia ativa, correlacionando os exemplos ao cotidiano. RESULTADOS: A primeira atividade foi com uma turma de crianças entre 7 e 9 anos de idade, usamos como estratégia de ensino o teatro de fantoches. O roteiro foi construído com base no tema de Doença de Chagas e Febre Amarela, em linguagem simples e clara, sobre como as doenças aparecem no cotidiano dos alunos e como eles poderiam preveni-las. A linguagem acessível possibilitou a interação com as crianças. Já no ensino médio, utilizamos um álbum seriado com desenhos ilustrativos à mão livre e distribuição de folders; os estudantes interagiram durante a apresentação e interpelaram com interesse em outros assuntos pertinentes à saúde, em especial, Infecções Sexualmente Transmissíveis (ISTs), resultando em uma apresentação extra, focada em: hepatites, sífilis, HIV e HPV. CONCLUSÕES E CONTRIBUIÇÕES: A realização do projeto educativo aliado à metodologia ativa aponta novas descobertas e caminhos, uma vez que ajuda na comunicação, contextualização, reflexão e construção coletiva do saber. Dessa forma, o processo ensino-aprendizagem foi eficaz para os acadêmicos participantes e alunos envolvidos. É importante evidenciar que o profissional de enfermagem, como educador, contribui para os avanços na promoção da 
saúde e na prevenção de doenças, ampliando sua visão quanto aos métodos de ensino, para uma comunicação compreensível e efetiva.

\section{Referências:}

1.Brasil. Ministério da Educação. Conselho Nacional de Educação. Câmara de Educação Superior. Resolução CNE/CES N. 3, de 07 de novembro de 2001. Brasília, 09 nov. 2001. Seção 1, p. 37. Brasília (DF): Ministério da Educação e Cultura; 2001.

2.BERBEL NAV. As metodologias ativas e a promoção da autonomia dos estudantes. Semina: Ciencias Sociais e Humanas. v.32, n.1, p. 25-40. 2011.

Descritores: febre amarela; educação em saúde, doença de Chagas. 


\title{
CAPACITAÇÃO E DOCÊNCIA: UMA VIA DE MÃO DUPLA
}

\author{
Thayanne Carlos Chaves \\ Carla Daniella Soares Santiago \\ Rizioléia Marina Pinheiro Pina \\ E-mail do autor correspondente: thayanne.chaves97@gmail.com
}

Introdução: Efetividade e satisfação do paciente durante a assistência são ideias que devem ser buscadas pelos profissionais durante o exercício, e possibilitadas pelas instituições por meio de artifícios que promovam o atendimento às necessidades da sociedade. Constantemente, novas informações surgem no meio social, novos métodos, técnicas e saberes, promovendo anseios e desejos durante a assistência. Os indivíduos estão cada vez mais conectados e informados, sendo bombardeados por ideias e novidades a todo o momento. É necessário que o profissional esteja capacitado a orientar o paciente sobre as informações fidedignas e a realizar as técnicas e métodos atuais, comprovados e eficazes cientificamente. Para tanto, é imprescindível que o profissional seja capacitado continuamente. É comum, nos indivíduos, a ideia de que, ao concluir um curso técnico ou uma graduação, o conhecimento fora totalmente assimilado e que, posteriormente, lhe restará somente o exercício profissional. Entretanto, a realidade é bem diferente, o conhecimento está em constante movimento e é necessário que os profissionais busquem artifícios para alcançá-lo. Portanto, essa ideia deve ser trabalhada desde a formação, para que se crie uma rotina de renovação e atualização do conhecimento a fim de capacitar e aperfeiçoar a assistência. Objetivo: Relatar experiências e reflexões de acadêmicos frente às situações encontradas durante $o$ Programa de Atividade Curricular de Extensão (PACE). Metodologia: Esta investigação se caracteriza como um estudo de natureza descritiva, qualitativa, do tipo relato de experiência, visando instigar uma reflexão acerca das situações apresentadas, sendo de suma importância para a formação acadêmica e profissional. O estudo surgiu a partir da observação durante as vivencias no PACE - Capacitação e Aperfeiçoamento da Equipe de Enfermagem na Pediatria, realizadas no período de Março a Julho de 2018, com acadêmicos de Enfermagem da Escola de Enfermagem de Manaus (UFAM) em uma unidade hospitalar pediátrica na cidade de Manaus. Resultados: Uma das estratégias usadas foi o encontro entre os profissionais e estudantes mediados por professores, com o objetivo de unir conhecimentos e alavancar a formação e assistência dos mesmos. Nós, estudantes, que estamos em contato diariamente com informações teórico-práticas, ficamos responsáveis, com o auxílio dos professores, por preparar e executar os mecanismos de transmissão de saberes, por meio de palestras, exposições, conversas, etc. e, assim, foi possível a fixação dos conhecimentos e o desenvolvimento da habilidade de docência, que é tão presente no exercício profissional da Enfermagem. Além disso, no próprio campo de trabalho, foi possível que os profissionais tivessem contato com os conhecimentos necessários para sua capacitação profissional, tendo possibilidade de tirar dúvidas e assimilar ao cotidiano do seu exercício, juntamente com seus colegas de trabalho, permitindo que toda a equipe pudesse obter as mesmas informações, possibilitando a similitude entre os mesmos. Ademais, foi criada uma via de mão dupla de informações, onde os estudantes tiravam dúvidas sobre a prática profissional e os 
profissionais atualizam-se sobre os novos conhecimentos, promovendo a interação entre os profissionais e estudantes com benefícios para ambos. Conclusões e contribuições ou implicações para a Enfermagem: $\mathrm{Na}$ área da saúde, o conhecimento atual está inteiramente ligado ao exercício profissional. Ele pode determinar o sucesso ou a deficiência na assistência ao paciente, assim como a habilidade de docência pode determinar a efetividade ou fracasso na prevenção de doenças e complicações. Portanto, é de suma importância que atividades que estimulem a habilidade de docência e que promovam a capacitação estejam presentes desde a formação até o cotidiano do exercício profissional, promovendo a integração e aperfeiçoamento da assistência e formação da equipe de enfermagem.

Descritores: Educação Continuada; Ensino; Educação em Enfermagem. 


\title{
A IMPORTÂNCIA DAS PRÁTICAS DE ENFERMAGEM PARA O APRIMORAMENTO DOS EGRESSOS DO CURSO DE ENFERMAGEM: UM OLHAR CRÍTICO REFLEXIVO
}

\author{
Evelyn Barros de Oliveira \\ Eline Araújo de Oliveira \\ Renildo Rodrigues Farias \\ Edson Silva do Nascimento \\ Rodrigues Ferreira de Souza \\ E-mail do autor correspondente: Evelynbarros1996@ outlook.com
}

Introdução: $O$ processo de formação em enfermagem busca lapidar um profissional com competências e habilidades técnicas/científicas para melhor aplicar a assistência de qualidade. As Diretrizes Curriculares Nacionais do Curso de Enfermagem (DCN/ENF), criadas pela resolução $n^{\ominus} 3 / 2001$, passaram por um novo movimento de reestruturação, denotando um novo perfil de profissional, com senso crítico reflexivo sobre o processo saúde-doença e sobre a realidade de uma população ${ }^{1}$. Nesse contexto, surgem os desafios para os egressos do curso de enfermagem, deparando-se, ao sair da faculdade, com as dificuldades em realizar suas tarefas assistenciais e gerenciais no mercado competitivo de trabalho. O medo, a falta de prática, ansiedade, insegurança são alguns pontos observados nos estudos sobre essa temática que mostra a necessidade de o egresso buscar qualificação em uma área de afinidade ${ }^{2}$. Objetivo: Discorrer sobre as dificuldades observadas pelo acadêmico nos futuros egressos do curso de enfermagem, assim como a importância das práticas de enfermagem para o aprimoramento profissional dos mesmos. Metodologia: Trata-se de um relato de experiência, sob a ótica do acadêmico de enfermagem, frente aos desafios na assistência após a formação. A reflexão surgiu durante as primeiras aulas práticas nas instituições de saúde. Resultados: A passagem da graduação para a profissão é vista pelos acadêmicos como um período árduo, de grandes descobertas, frustrações, entusiasmos e realizações. Arcar com a liderança constituiu além de um desafio, livrar-se do preconceito de terem pouca experiência e idade muito jovem/jovem adulta, obter confiabilidade da equipe na mudança de papel dentre aqueles que atuavam anteriormente como técnico (a) de enfermagem; solucionar as lacunas na formação, em particular, questões gerenciais e de liderança da equipe. A singularidade do cuidado em áreas de especialidades e as competências gerais da prática cotidiana do enfermeiro, que teriam que ser adquiridas durante a formação, são os problemas relacionados à competência e a habilidade técnica. Percebemos que os profissionais recém-formados têm dificuldade em associar o conteúdo teórico à prática assistencial. Também sugerem que o processo de formação dos enfermeiros necessita ser baseado em princípios que valorizem não apenas a racionalidade, mas a associação ao cotidiano da saúde. Conclusão e contribuições ou implicações para a enfermagem: $O$ enfermeiro deve aparentar-se receptivo para ouvir e aprender a compartilhar saberes entre os membros da equipe, reconhecer seu limite e até onde vai sua capacidade técnica para tal tema ou procedimento. Os estágios realizados durante a graduação servirão apenas como base para a preparação do profissional, porém não são suficientes para o enfrentamento em um mercado de trabalho tão competitivo. O mesmo deve buscar capacitar-se através 
de cursos de capacitação, pós-graduação, residência multiprofissional, dentre outros, para assim desempenhar sua assistência diferenciada e qualificada.

\section{Referências:}

1 - Souza FA, Paiano M. Desafios e dificuldades enfrentados pelos profissionais de enfermagem em início de carreira. Rev. Min. Enferm.;15(2): 267-273, abr./jun., 2011 2 - SILVA DGV et al. Os desafios enfrentados pelos iniciantes na prática de enfermagem. Rev. Esc. Enferm. USP; 44(2):511-6, 2010

Descritores: Enfermagem; Formação profissional; Prática de enfermagem. 


\title{
AS DIFICULDADES VIVENCIADAS POR ACADÊMICOS DE ENFERMAGEM FRENTE AO ENSINO E PESQUISA: UM RELATO DE EXPERIÊNCIA
}

\author{
Renildo Rodrigues Farias \\ Eline Araújo de Oliveira \\ Evelyn Barros de Oliveira \\ Edson Silva do Nascimento \\ Rodrigues Ferreira de Souza \\ E-mail do autor correspondente: renildo.enfermeiro@gmail.com
}

Introdução: Entendemos que a junção da pesquisa com o ensino na graduação e com o sistema de saúde vem conquistando espaços por pesquisadores, não deixando de ser um desafio para a enfermagem ${ }^{1}$. A busca por conhecimento científico na graduação contribui para a formação do graduando, dando competência para solucionar as dificuldades do saber profissional através da pesquisa. É compreensível a visão do acadêmico voltado para este assunto, o que torna importante o aperfeiçoamento e a criação de ferramentas modernas, por parte do corpo docente, que contribuam para o ensinamento que atraia o discente para dar continuidade à pesquisa durante sua vida acadêmica e profissional ${ }^{2}$. Objetivo: Identificar as dificuldades encontradas pelos acadêmicos de enfermagem na realização de pesquisas científicas e estimular o desenvolvimento precoce de pesquisa. Metodologia: Trata-se de um resumo, do tipo relato de experiência, sobre o ensino e pesquisa, e as dificuldades e desafios enfrentados pelos acadêmicos do curso de enfermagem do Centro Universitário FAMETRO, vivenciado a partir da elaboração do trabalho de conclusão de curso - TCC. Resultados: Observou-se que as dificuldades identificadas estão relacionadas à falta de conhecimento quanto às metodologias de pesquisas que vão além de como conduzir um estudo, que tipo de estudo está sendo realizado, dentre outras dificuldades como formatação, habilidades com as normas pedidas para a execução de trabalhos científicos e poucas habilidades com a escrita, o que torna difícil o envolvimento com o ensino e pesquisa. Conclusões e contribuições ou implicações para a Enfermagem: Portanto, os desafios no desenvolvimento de pesquisas em enfermagem existem, mais podem ser superados, tendo em vista as necessidades da enfermagem de produzir conhecimento ainda na graduação objetivando, dessa forma, contribuir para a formação do profissional, e colocando em evidência a profissão, contribuindo para a formação do enfermeiro e conquistando seu espaço no meio multiprofissional, através da elaboração do saber.

\section{Referências:}

1. MEIRA, M.D.D; KURCGANT, P. Avaliação da formação de enfermeiros segundo a percepção de egressos. Acta Paul Enferm. 21(4): 556-61, 2008.

2. OLIVEIRA, Marcela Pereira; Desafios da pesquisa científica na enfermagem: práticas e possibilidades. Volta Redonda: UniFOA, 2016. 67p: 11.

3.COLLET, Neusa; SCHNEIDE, Jacó Fernando; CORREA, Adriana Katia. A Pesquisa em Enfermagem: Avanços e Desafios. R. Bras. Enferm, Brasilia. v. 53, n.1,p. 75-80, jan./mar. 2000

Descritores: Pesquisador; Enfermagem; Formação Profissional. 


\title{
VIVÊNCIA DAS ACADÊMICAS DE ENFERMAGEM COM A TELESTOMATERAPIA COMO FERRAMENTA DE ESTUDO E AMPLIAÇÃO DE CONHECIMENTOS: UM RELATO DE EXPERIÊNCIA
}

\author{
Lenina Jordana Bastos de Macedo \\ Bianca Barbosa Farias \\ Eunice Beatriz Ribeiro Bastos \\ Leila Gomes Matos Torres \\ Nany Camilla SevalhoAzuelo \\ Eliana Marques Gomes \\ E-mail do autor correspondente: leninajordana16.1j@gmail.com
}

Introdução: A Estomaterapia é uma área da saúde responsável por tratar e reabilitar pessoas com perda da integridade da pele - lesões agudas e crônicas ocasionadas por doenças como o Diabetes Mellitus -, estomia respiratória (traqueostomia), estomias digestivas (colostomia, ileostomia, jejunostomia, e urostomia) e incontinência urinária e anal; e capacitar os futuros profissionais, além dos que já atuam, se torna indispensável, uma vez que a qualidade do serviço prestado a indivíduos portadores dessas condições deve ser soberana. A tecnologia de informação e comunicação, aliada às ciências da saúde, tem a possibilidade de contribuir ainda mais para a melhoria contínua na capacitação de pessoas que estão localizadas em lugares remotos e de difícil deslocamento, como no interior amazonense. De tal forma, a Telestomaterapia surge como a união entre esses dois campos, a fim de proporcionar qualificação para este público de professionais. Objetivo: Compartilhar a experiência de vivência das autoras, através dos sucessos e dificuldades, sobre o projeto de Telestomaterapia. Metodologia: Aborda um relato de experiência descritivo, realizado na Universidade do Estado do Amazonas (UEA), mais precisamente na Escola Superior de Ciências da Saúde (ESA), no Laboratório de Estomaterapia (LABEST). Para que o projeto vivenciado acontecesse em forma de Educação à Distância, criou-se uma parceria com o grupo de Telessaúde da Universidade, na qual se utilizou o ponto de Telemedicina para a transmissão das formações. As aulas aconteciam em tempo real, com interação entre o formador e a turma; e, nos casos em que algum município não pudesse acompanhar a aula, o conteúdo e material utilizado (incluindo a vídeo-aula do dia) ficavam disponíveis na plataforma do Telessaúde para acesso posterior, não permitindo que o município em questão fosse prejudicado. A vivência se deu no período de agosto de 2017, até agosto de 2018, incluindo dias letivos e alguns dias dos períodos de férias. Resultados: Mediante as práticas desenvolvidas no decorrer do projeto, se tornou notório o quanto o interior possui dificuldade de capacitação, por motivos como deslocamento até a capital, a oferta de cursos nos próprios municípios e a conexão com a rede de internet, sendo esse último fator, um ponto de dificuldade na execução de algumas atividades oferecidas pelo projeto da universidade. Em unanimidade, todos os municípios contatados aceitaram, com extrema abertura, a oferta das capacitações na área de estomaterapia, mostrando-se sempre solícitos em disponibilizar equipes com o máximo de especialidades (dentro das solicitadas: técnico de enfermagem, enfermeiro e médico). Na posição de estudantes, o empoderamento adquirido através das participações em organizar a listagem de municípios, entrar em contato com os mesmos, explicar sobre o que se tratavam as 
capacitações, trouxe noção sobre o quanto pensar em saúde para o interior é importante e elaborar projetos para que essas localidades sejam alcançadas, apenas acresce ao sistema de saúde, e o principal alvo favorecido é a população, que recebe um tratamento mais qualificado. Em contrapartida, os municípios apesar de estarem dispostos a participar das formações, alguns faziam reclamações quanto à falta de pessoas especialistas que soubessem manusear o material disposto no ponto de Telessaúde. Somado a isso, havia alguns pontos como computadores sem manutenção, ou até mesmo que foram levados para a capital (Manaus) para conserto e extrapolaram o prazo para retorno, deixando, assim, a equipe da cidade desfalcada em relação a esses instrumentos que eram necessários para que as transmissões acontecessem. Conclusões e implicações para a Enfermagem: Portanto, ofertar qualidade no atendimento aos pacientes é garantir uma assistência humanizada, integral e que forneça equidade ao tratar essas condições individuais. Além disso, alinhar as tecnologias atuais para que, em casos de necessidade, o ensino a distância aconteça até mesmo em áreas remotas, engrandece o conhecimento de quem está recebendo as informações como também para quem está fornecendo, seja através da organização ou a própria capacitação fornecida. Apesar das dificuldades encontradas, continuar investindo em conhecimento difuso através de sistemas de comunicação traz grandes benefícios para a área da saúde e para os profissionais que a ela pertencem.

\section{Referências:}

1.CARVALHO, P. C. K. DE; ARCE, E. V. Satisfação humana diante dos recursos da Telemedicina. Reverte - Revista de Estudos e Reflexões Tecnológicas da Faculdade de Indaiatuba, 2009.

2. SANTOS, J. B. DOS et al. Avaliação e tratamento de feridas orientações aos profissionais de saúde, 2011.

3. ASSOCIAÇÃO BRASILEIRA DE ESTOMATERAPIA. Estomaterapia - Histórico. Disponível em: <http://www.sobest.org.br/texto/6>. Acesso em: 08/10/2018.

Descritores: Educação a Distância; Educação em Enfermagem; Estudantes de Enfermagem. 


\title{
EDUCAÇÃO EM SAÚDE SOBRE CONSUMO DE SAL E AÇUCAR ENTRE ESCOLARES: UM RELATO DE EXPERIÊNCIA
}

\author{
Eunice Beatriz Ribeiro Bastos \\ Nany Camilla SevalhoAzuelo \\ Leila Gomes Matos Torres \\ Lenina Jordana Bastos de Macedo \\ Elaine Cristina Santana Cordovil \\ E-mail do autor correspondente: ebrb.enf@uea.edu.br
}

Introdução: Tem sido cada vez mais habitual no cotidiano, principalmente de crianças escolares, o consumo exacerbado de sal e açúcar em produtos consumidos como opções de lanches não saudáveis, que possuem grande quantidade desses ingredientes. $\mathrm{O}$ excesso de açúcar contribui no ganho de peso corporal e pode aumentar a incidência de doenças como a obesidade e o diabetes, assim como o excesso de sal é responsável por diversos problemas de saúde como hipertensão e alteração na absorção de nutrientes. ${ }^{(1)}$ Para a redução do consumo desses alimentos, a educação em saúde no âmbito escolar tem como função realizar um processo de construção de conhecimento e auxiliar na tomada de decisões, contribuindo para o reforço de hábitos saudáveis. ${ }^{(2)}$ Objetivo: Descrever a experiência de educação em saúde com escolares durante a disciplina de Enfermagem no Processo de Cuidar na Saúde da Criança. Metodologia: Relato de experiência, de prática de educação em saúde durante a disciplina de Enfermagem no Processo de Cuidar na Saúde da Criança, realizada com escolares, em uma escola estadual de Manaus-AM em 2018. Resultados: Foi realizada uma ação de educação em saúde sobre o consumo de sal e açúcar, no qual foi abordada, em forma de palestra, uma explanação acerca dos prejuízos do consumo dessas substâncias e retirada de dúvidas conforme ocorriam. Representação da alimentação - na primeira atividade, foi solicitado que todos os alunos da sala fizessem um desenho que retratasse seu consumo durante os lanches, sendo estes café-da-manhã ou lanche em geral, e apresentassem para a turma. Mesmo na escola, sendo disponibilizados frutas, mingaus e sucos para o café-da-manhã, a fim de promover hábitos saudáveis, alimentos como esses foram pouco citados entre as crianças, identificando assim que os alimentos menos saudáveis são os mais frequentes em seu consumo. A referência aos alimentos mais consumidos durante os lanches foram bolacha, bolo, pão, suco industrializado e refrigerante. No encerramento da atividade, com o objetivo de demonstrar a quantidade de sal e açúcar consumido nos alimentos e preferência da turma, foi apresentada, de forma expositiva, a quantidade desses ingredientes em alimentos comuns que são consumidos no dia a dia. Devido a essas crianças não terem um entendimento sobre quantidade em gramas, levamos uma balança de cozinha, copo descartável transparente, açúcar e sal, e então demonstramos lhes indicando se era "pouco", "médio" ou "muito", e então eles entendiam a quantidade. Por exemplo, se tivesse dado uma quantidade aparentemente "pouca" e eles achassem que era pouco, falávamos "vocês já imaginaram comer 4 colheres de açúcar?" e então eles percebiam o quão prejudicial poderia ser. Conclusões e contribuições para a Enfermagem: Durante a graduação, nos apropriamos de que a educação faz parte do exercício profissional do enfermeiro e, desde acadêmicos, atuamos como educadores. 
Nesse processo, tivemos a oportunidade de ter um primeiro contato com crianças na disciplina, onde tivemos que adequar a abordagem a uma linguagem simples e utilizar uma metodologia que chamasse a atenção das mesmas, assim como criamos a capacidade de atender as particularidades de cada criança. Através da educação em saúde pudemos orientar sobre os malefícios de uma alimentação não saudável à criança na idade escolar, os incentivando a uma escolha correta de alimentos para que adquiram uma melhor qualidade de vida. $^{(3)}$

\section{Referências:}

1. Associação Brasileira de Nutrição. Os benefícios da redução do consumo do sal e açúcar. Rio de Janeiro, 2014.

2. Gomes AM, Santos MS dos, Finger D, Zanittini A, Franceshi VE, Souza JB de, Haag FB, Silva DJ da. Refletindo sobre as práticas de educação em saúde com crianças e adolescentes no espaço escolar: um relato de extensão. Ponta Grossa, 2015;11(3).

3. Sociedade Brasileira de Pediatria. Manual de orientação para a alimentação do lactente, do pré-escolar, do escolar, do adolescente e na escola/Sociedade Brasileira de Pediatria. Departamento de Nutrologia, $3^{\text {a }}$. ed. Rio de Janeiro, RJ: SBP, 2012. 148 p.

Descritores: Educação em saúde; Alimentação Saudável; Estudantes de Enfermagem. 


\title{
CONTRIBUIÇÕES DA MONITORIA PARA O PROCESSO DE FORMAÇÃO ACADÊMICA DO ENFERMEIRO - RELATO DE EXPERIÊNCIA
}

\author{
Victória de Assis Silva \\ Sibele Naiara Ferreira Germano \\ Paulo Franco Cordeiro de Magalhães Júnior \\ E-mail do autor correspondente: vas.enf17@uea.edu.br
}

Introdução: O Programa de Monitoria é um Programa Institucional realizado na maioria dos cursos de graduação das Universidades, pautado pela Lei ${ }^{\circ}$ 9.394\%/96, ofertado para alunos adequadamente inscrito nos cursos de graduação de sua unidade. O programa é um método de ensino-aprendizagem, sendo este uma ferramenta usada para incentivar a docência no aluno-monitor, cujas atividades desenvolvidas possibilitam a ampliação da formação acadêmica, estimulando o acadêmico a se apropriar de sua função educadora quanto profissional de saúde ${ }^{1}$, recurso essencial para promoção de saúde e prevenção de doença. Objetivos: Relatar a experiência obtida no programa de monitoria acadêmica da Universidade do Estado do Amazonas (UEA), com a finalidade de destacar a relevância desse método pedagógico para a formação profissional de enfermagem para o cuidado em saúde. Metodologia: Estudo descritivo, do tipo relato de experiência. A monitoria teve vigência de um semestre (2018.2), no período de 15 de agosto a 09 de dezembro, cujas ações foram vivenciadas por discentes da Escola Superior de Ciências da Saúde (ESA). Resultados: Para efetivação do aluno-monitor, é necessário que já tenha cursado a disciplina, de alvo da monitoria, e alcançado média de aprovação, além de passar por um processo de classificação, realizado através de provas no qual o aluno deve obter nota igual ou superior a 7(sete). Dessa forma, obtém-se a lista de bolsista e voluntários. Referente às atividades exercidas pelo aluno monitor, são atribuídas: auxiliar o professor na realização de exercícios em sala e laboratório, orientar os alunos esclarecendo e tirando dúvidas quanto ao conteúdo da disciplina, além de realizar outras tarefas que propiciem o seu aprofundamento na disciplina. Tais atividades desenvolvem habilidades de comunicação na docência, além de ocorrer o aperfeiçoamento quanto ao conteúdo, já que é necessária a revisão do assunto para a transmissão de conhecimento. Quanto aos alunos monitorados, foi possível notar que os mesmos se apresentam mais confortáveis a esclarecer dúvidas com os monitores, pois sentem maior liberdade em questionar outro aluno. Conclusões e contribuições ou implicações para a Enfermagem: O conjunto de atividades realizadas pelo aluno monitor aperfeiçoa ou mesmo estimula competências importantes, como: comunicação e interação ativa e colaboração interprofissional, cuja docência se faz presente diretamente em suas atividades profissionais, como na Enfermagem ${ }^{2}$. Logo, o Programa de monitoria apresenta-se efetivo quanto a seu objetivo, além de ter um papel importante na formação acadêmica tanto do aluno monitor quanto do aluno monitorado trazendo benefícios a ambos no processo de aprendizagem e profissionalização, através da troca de conhecimento, onde ambos aprendem com essa atividade. 


\section{Referências:}

1. SCARPARO HAAG, Guadalupe et al. Contribuições da monitoria no processo ensinoaprendizagem em enfermagem. Revista Brasileira de Enfermagem, v. 61, n. 2, 2008.

2. COLEBRUSCO DE SOUZA, Geisa et al. Trabalho em equipe de enfermagem: circunscrito à profissão ou colaboração interprofissional?. Revista da Escola de Enfermagem da USP, v. 50, n. 4, 2016.

Descritores: Enfermagem, Monitoria, Formação 


\title{
VIVÊNCIAS DE ACADÊMICOS DE ENFERMAGEM EM UMA UNIDADE DE TERAPIA INTENSIVA
}

\author{
Marcela Catunda de Souza \\ Viviane Santana de Andrade \\ Lie Tonaki \\ Elisângela de Fátima Ponte Frota
}

E-mail do autor correspondente: mcsm.enf@uea.edu.br

Introdução: O curso de graduação em enfermagem, da Universidade do Estado do Amazonas (UEA), tem por finalidade a formação de enfermeiros generalistas, capacitados a atuar de forma plena em todos os campos da enfermagem, atendendo às expectativas do Sistema Único de Saúde ${ }^{1}$ Apesar disso, conforme o graduando avança dentro dos períodos do curso, acaba por criar afinidades em determinadas matérias e áreas específicas. A UEA utiliza o tripé ensino, pesquisa e extensão, como forma de incentivar o acadêmico a buscar conhecimentos que ultrapassem as aulas pertencentes à matriz curricular. As ligas acadêmicas são exemplos de extensões universitárias, voltadas a aprendizagem, desenvolvimento e aperfeiçoamento de uma área mais delimitada de maneira didática, científica e cultural ${ }^{2}$. A Liga Amazonense de Enfermagem em Terapia Intensiva (LAETI) foi fundada em 2016 com finalidade de integrar o ensino, a pesquisa e a extensão em terapia intensiva e áreas afins. Durante o seu funcionamento, tem sido responsável pela inserção mais acentuada de acadêmicos na enfermagem intensiva. Objetivos: Objetiva-se relatar a experiência de acadêmicos de enfermagem pertencentes à LAETI. Metodologia: Trata-se de um relato de experiência das atividades desenvolvidas por acadêmicos de enfermagem, oriundos de processo seletivo para participação no ciclo 2017-2018 da LAETI. Para a construção da área de extensão, os membros ligantes cumpriram o total de quinze plantões de seis horas na Unidade de Terapia Intensiva (UTI) da Fundação Hospital Adriano Jorge, sob supervisão dos enfermeiros associados ao Instituto de Enfermeiros Intensivistas do Amazonas (IETI).Resultados: As ações realizadas pelos membros ligantes, especificamente voltadas à extensão, contemplavam questões assistenciais, ao ficarmos responsáveis integralmente por todas as necessidades de pacientes de nível complexo e com risco iminente de morte. Para isso, eram realizadas as cinco etapas do Processo de Enfermagem, voltadas ao paciente crítico. As intervenções realizadas em maior quantidade eram a sondagem vesical, curativos, aspiração, balanço hídrico, gasometria arterial e verificação dos parâmetros ventilatórios, além da oportunidade de participar das questões burocráticas pertinentes à admissão e alta de pacientes. As atividades subsidiaram também o desenvolvimento de habilidades não técnicas como a tomada de decisão, raciocínio clínico, pró-atividade, comunicação efetiva em saúde e o aprimoramento do trabalho interdisciplinar em equipe, características imprescindíveis do enfermeiro intensivista que está à beira do leito. As ações tinham supervisão e orientação dos profissionais enfermeiros da UTI, certificando-se de que nada era feito com dúvida, garantindo sempre a segurança do paciente. Conclusões e contribuições ou implicações para a Enfermagem: A extensão universitária contribui de maneira mútua, tanto para o serviço, quanto para os acadêmicos. O serviço é beneficiado quando os profissionais 
recebem apoio dos acadêmicos para realização de tarefas, assim podem manter o foco àqueles pacientes mais instáveis. Aos acadêmicos, é agregada a oportunidade de aumentar o contato com o paciente crítico em um ambiente restrito durante longo período de tempo, além da chance de exercer habilidades técnicas de grande responsabilidade, relacionadas ao manejo do paciente crítico. Estar envolvido na rotina hospitalar, durante atividades práticas, foi essencial para aprimorar o raciocínio clínico, compreender a fisiopatologia dos pacientes internados e entender o cotidiano de um profissional. A LAETI é essencial para a inserção desses alunos durante vivência prática dentro de uma UTI, podendo incentivar o acadêmico a buscar especializações na área, conhecer e se envolver com profissionais que agreguem maior conhecimento sobre a temática.

\section{Referências:}

1. Universidade do Estado do Amazonas. Enfermagem Apresentação. [Acesso em: 14 out 2018]. Disponível em http://cursos3.uea.edu.br/apresentacao.php?cursoId=57.

2. Fernandes PMP; Miriani, AW. O ensino médico além da graduação: ligas acadêmicas. Diagn Tratamento. 2011; 16(2): 50-1.

Descritores: Unidades de Terapia Intensiva; Educação em Enfermagem. 


\title{
PROMOVENDO SAÚDE PARA CRIANÇAS, POR MEIO DE MATERIAIS LÚDICOS, EM UMA ESCOLA NO INTERIOR DO AMAZONAS
}

\author{
Elison Gonçalves da Silva \\ Ketllem Dione dos Santos de Abreu \\ Rizonaldo da Silva Pereira \\ Gabrielle Silveira Rocha Matos
}

E-mail do autor correspondente: elisongoncalves1@gmail.com

Introdução: A infância constitui uma fase estratégica para o desenvolvimento de ações de promoção da saúde, visto que os comportamentos assimilados tendem a ser reproduzidos na vida adulta ${ }^{1}$. Nessa perspectiva, para desenvolver propostas de educação em saúde em diversos âmbitos de socialização da criança, foi instituído o Decreto de $\mathrm{n}^{\circ}$ 6.286, de 05 de dezembro de 2007, que cria o Programa Saúde na Escola-PSE². Atividades voltadas para a educação em saúde na infância são necessárias e um instrumento mediador é o lúdico, o que torna o processo de ensino-aprendizagem uma construção prazerosa e facilitadora para a promoção de saúde ${ }^{3}$. Este projeto de extensão multidisciplinar buscou estabelecer uma relação recíproca com diversos saberes da área da saúde, com o intuito de proporcionar um bem-estar amplo para essas crianças. Objetivos: Promover a educação em saúde em crianças utilizando a estratégia do brincar na perspectiva de elucidar a importância da higiene pessoal e do bem-estar. Metodologia: O projeto de extensão universitária foi desenvolvido em uma escola municipal em Coari, no interior do Amazonas, sendo o público-alvo, crianças de 04 a 05 anos. As ações aconteceram em cinco dias na brinquedoteca para diversas turmas nos turnos matutino e vespertino. O projeto foi desenvolvido em três fases: 1) Capacitação dos discentes, com reuniões e seleção dos temas (higiene bucal, lavagem das mãos e banho correto); 2) Construção de materiais lúdicos (jogo da memória, contendo os passos da forma correta da lavagem, mãos de cartolina, uma limpa e a outra suja com parasitas e verminose, uma boca, escova e creme dental de tamanho ampliado, e socialização de uma música que ensina os passos para uma boa higiene corporal; 3) Intervenção na escola, com palestras abordando os temas, a utilização e socialização dos materiais lúdicos, terminando com o ato de brincar. Resultados alcançados: Por meio das ações, pode-se notar a participação das crianças nas atividades propostas, observando assim, sua interação e socialização no momento das intervenções. A internalização do conhecimento de cada um aconteceu por meio do ato de brincar com o material lúdico, observando seu grau de desenvoltura. Também foi possível, através de conversas informais com as professoras das turmas, identificar se ocorreu melhora nas crianças no cuidar de sua higiene, o que de fato, segundo relatos, houve uma evolução significativa. Conclusões e contribuições ou implicações para a Enfermagem: Este projeto amplia a visão da educação em enfermagem e a importância da saúde da criança, pois é um público evidenciado pelas ações assistencialistas, mas em relação à prevenção educativa, ainda há algumas lacunas. Também faz compreender o indivíduo como um todo e em suas fases, propiciando o desenvolvimento do bem-estar, trabalhando a educação e saúde na escola com intervenções pontuais. Dessa forma, a escola é um espaço social de grande interação que possibilita quebra de paradigmas e construção de novos saberes. Assim a educação está 
em reciprocidade com o comportamento e hábito que determinam a saúde coletiva e individual do sujeito.

\section{Referências:}

1 - FROTA, M. A. Et al. Reflexão sobre políticas públicas e estratégicas na saúde integral da criança. Enfermagem em foco. v. 1, n. 3, 2011.

2 - FIGUEIREDO, T. A. M.; MACHADO, V. L. T.; ABREU, M. M. S. A saúde na escola: um breve resgate histórico. Ciência \& Saúde Coletiva. v. 2, n. 15, p. 397-402, 2010.

3 - SILVA, A. A. da. Et al. O lúdico como estratégia de promoção da saúde: integrando universidade e criança de comunidades ribeirinhas e ru rais. Universidade Federal do Vale do São Francisco UNIVASF. IX Mostra de Extensão. 2014.

Descritores: Educação em enfermagem; Saúde da criança; Promoção da saúde. 


\title{
A VIVÊNCIA DO ACADÊMICO DE ENFERMAGEM NA PRÁTICA DA DISCIPLINA DE ENFERMAGEM NO PROCESSO DE CUIDAR NA SAÚDE MENTAL
}

\author{
Brenda de Moraes Brito \\ Débora Oliveira Marques \\ Douglas Siqueira de Brito \\ Everdan da Silva Souza
}

E-mail do autor correspondente: brenda.mbrito@ hotmail.com

Introdução: A disciplina de Enfermagem no Processo de Cuidar na Saúde Mental para o curso de enfermagem é de extrema importância para tanto despertar nos alunos o interesse, quanto desenvolver o olhar humanizado. O hospital psiquiátrico legalmente deveria ter dado lugar a alas psiquiátricas em hospitais gerais da cidade de Manaus ${ }^{1}$. No entanto, ainda permanece em atividade como hospital de custódia, o qual é a única opção de tratamento para pacientes emergenciais na capital do Amazonas. Assim, a prática no ambiente de hospital psiquiátrico procurou manifestar a necessidade de relatar o modelo estrutural de gestão da saúde nesse recinto e, consequentemente, gerar o questionamento sobre a realidade da saúde mental e anseio de mudança na forma de tratamento desses pacientes. Objetivos: Relatar a experiência de vivência em um ambiente de hospital psiquiátrico, um modelo obsoleto ainda atuante, na cidade de Manaus. Metodologia: $\mathrm{O}$ cenário do estudo foi um centro psiquiátrico localizado no Município de Manaus. Integra o estágio supervisionado da disciplina Processo de Cuidar da Saúde Mental do curso de Enfermagem da UEA. Dessa forma, ocorreu no período de 8 a 11 de setembro de 2018, no Centro Psiquiátrico, com a apresentação do hospital no primeiro dia, a entrevista com paciente no segundo e a coleta de dados, baseada nos prontuários de 2007 a 2018, para a realização do estudo de caso de esquizofrenia, no terceiro, como também a visita domiciliar no quarto dia. Resultados: No primeiro dia de prática, foram apresentadas a história do hospital e, em seguida, todas as dependências do prédio, onde se observou o estado precário do lugar em que se encontram os pacientes. No segundo dia ocorreu a divisão de pacientes por grupo, ocorrendo entrevista com a paciente $\mathrm{RSO}$, a qual não pôde responder as perguntas, pois apresentava-se com verbigeração excessiva e solilóquios. No terceiro dia, foi permitido, pelo Serviço de Arquivo Médico e Estatística, que a avaliação dos prontuários da paciente fosse realizada. Foram observados registros de 2007 a 2018, onde constavam diversas internações e informações que comprovavam seu quadro clinico, bem como seu principal diagnóstico: Esquizofrenia. No quarto e último dia, realizou-se a visita domiciliar com o objetivo de verificar as condições de moradia da família, o que possibilitou a conversa com alguns familiares. A residência era humilde e não foi permitido fotografar o local. O período de aula prática proporcionou experiências que contribuíram para a desmitificação do conhecimento sobre o doente mental e o hospital psiquiátrico. Conclusões e contribuições ou implicações para a Enfermagem: A interação prática em saúde mental é relevante para fomentar o conhecimento e a segurança da experiência vivida pelo acadêmico, uma vez que amplia as noções dos modelos atuantes de gestão hospitalar e suas áreas da saúde, instiga a busca por leis e diretrizes sobre as condições biopsicossociais desses ambientes e desenvolve o senso crítico da qualidade de serviço proposto para os pacientes. Além disso, propõe aos 
indivíduos sempre a melhora clínica, com dignidade do tratamento, e a reintegração ampla na sociedade.

\section{Referências:}

1. Lopes RS. Entre a atenção à saúde e a legalidade: a atuação do hospital de custódia e tratamento psiquiátrico (parte I). Rev Zona de Impacto. 2013 [acesso 14 de Outubro de 2018]; 32(1).

Disponível em:http://www.revistazonadeimpacto.unir.br/Randiza\%20Lopes\%20parte\%20I\%20Zona \%20de\%20Impacto\%2015_1.pdf

Descritores: Saúde Mental; Enfermagem Psiquiátrica; Transtornos Mentais. 